\title{
Non-masticatory uses of anterior teeth of Sima de los Huesos individuals (Sierra de Atapuerca, Spain)
}

\author{
Marina Lozano ${ }^{\mathrm{a}, *}$, José M. Bermúdez de Castro ${ }^{\mathrm{b}}$, Eudald Carbonell ${ }^{\mathrm{a}}$, Juan Luis Arsuaga ${ }^{\mathrm{c}}$ \\ ${ }^{a}$ Institut Català de Paleoecologia humana i Evolució Social (IPHES), Area de Prehistoria. Facultad de Letras, Universitat Rovira i Virgili, \\ Plaza Imperial Tarraco 1, 43005 Tarragona, Spain \\ ${ }^{\mathrm{b}}$ Centro Nacional de Investigación sobre Evolución Humana (CENIEH), C/Toledo 4-5, 09004 Burgos, Spain \\ ${ }^{c}$ Centro de Evolución y Comportamiento Humanos, C/Sinesio Delgado 4, pabellón 14, 28029 Madrid, Spain
}

\section{Keywords:}

Cultural wear features

Anterior dentition

Paramasticatory activities

Middle Pleistocene

Homo heidelbergensis

\begin{abstract}
A B S T R A C T
In this study we examine the labial and occlusal surfaces of incisors and canines of hominins recovered from the Sima de los Huesos (SH), middle Pleistocene site, in order to establish the possible extramasticatory use of anterior teeth. We have compared the microwear of these fossils with microwear from the anterior teeth of Australian Aborigines, a population characterized by ethnographic evidence of the use of their teeth as a third hand. These two samples of teeth were microscopically analyzed using Scanning Electron Microscopy (SEM). Our results support the "cultural" origin of microwear observed on fossil teeth: we conclude that the SH hominins used their anterior teeth as a "third hand" for para- or extra-masticatory activities.
\end{abstract}

\section{Introduction}

Prehistoric societies, and all non-industrialized human groups in general, present a high degree of dental wear that has been the object of many studies (Brace and Molnar, 1967; Brace and Mahler, 1971; Molnar, 1971; Kaifu, 2000; Bermúdez de Castro et al., 2003; Kaifu et al., 2003). Dental wear is not only related to diet, since wear related to other cultural factors has been identified on anterior teeth. The wear features associated with a cultural etiology are the consequence of using the anterior part of the dental arcade for tasks that are not directly related to the chewing of food. Diet-related features and those of extra-masticatory or cultural etiology are differentiated on the basis of the larger size (width, length), disposition, location (more frequent in anterior teeth), orientation, and regularity of extra-masticatory or cultural features (Lalueza Fox, 1992).

In 1973, de Lumley showed the presence of some striations on the anterior teeth of the individuals from the Hortus' site (France). These striations only appeared on the labial surface of anterior teeth and may not have represented a diet-related etiology. De Lumley (1973) suggested that this wear was caused by the action of holding meat in the anterior teeth and cutting it with a stone flake.

\footnotetext{
* Corresponding author.

E-mail address: mlozano@prehistoria.urv.cat (M. Lozano).
}

In the cutting process, hominins would accidentally strike their dental enamel with the flake and cause gouges similar to cutmarks found on faunal remains.

Similar striations were later reported in fossil hominins from middle and late Pleistocene sites such as Shanidar (Trinkaus, 1983), Krapina (Lalueza Fox and Frayer, 1997), Atapuerca-Sima de los Huesos, La Quina 5, Cova Negra (Bermúdez de Castro et al., 1988), Saint Bras, Angles-sur-L'Anglin, Kabwe, Mauer (Lalueza Fox and Pérez- Pérez, 1994; Puech, 1979, 1982), and Tabun I (Lalueza Fox, 1992). Striations such as these have also been documented in anatomically modern humans of the Chalcolithic site of Mehgarh (Lukacs and Pastor, 1988), paleoindian individuals from several North American sites (Buhl, Spirit Cave, Wilson Leonard Burial III; Green et al., 1998), and on the teeth of Eskimos, Aleutians, Tasmans, Fueguians, Australian Aborigines, Arikara, Illinois Bluff, and Puye Indians (Merbs, 1968; Lalueza Fox, 1992; Bax and Ungar, 1999).

Previously, we performed an experimental analysis (using 23 anterior teeth obtained from surgical extractions) to test similarity between the cutmarks on bone and vestibular striations on human teeth (Lozano et al., 2004; Lozano, 2005). The aim of the experiment was to generate cutmarks on the labial surface of the teeth and compare them with the vestibular striations found in fossils. Cutmarks were made with raw materials and tool types similar to those most often found at the Sierra de Atapuerca sites: flakes of flint, sandstone, quartz, and quartzite. Then the teeth were divided into groups. In order to simulate the dental arcade, each set of teeth 
Table 1

Experimental cutmarks mean maximum widthsse $\mathrm{e}^{\mathrm{a}}$

Experimental cutmarks

\begin{tabular}{lll}
\hline & Right-hand & Left-hand \\
\hline Quartz & $46.3(17.5)$ & $36.2(12.71)$ \\
Quartzite & $35.0(13.2)$ & $33.2(7.71)$ \\
Sandstone & $39.1(17.5)$ & $35.5(9.7)$ \\
Flint & $39.1(14.3)$ & $53.9(30.2)$ \\
\hline
\end{tabular}

a Standard deviations are in parentheses. Measurements are in micrometers ( $\mu \mathrm{m})$.

was glued in their respective position to a buccal protector (similar to those used by sportsmen). In the experiment we were helped by two assistants, one right-handed and one left-handed. Each assistant inserted into his mouth a buccal protector with one set of teeth. They made cuts on the labial surface by simulating cutting some kind of material. The same procedure was repeated with different sets of teeth and flakes of different lithic materials. Results showed that experimental cutmarks have the same morphology as vestibular striations found on Sima de los Huesos (SH) anterior teeth (Lozano et al., 2004; Table 1). This previous work allows us to identify extramasticatory marks in SH and in Australian Aborigines teeth.

However, in addition to cutmarks, wear features of non-dietary etiology also appear on the occlusal surfaces of anterior teeth (Ryan and Johanson, 1989; Minozzi et al., 2003). In the present study, we examine the labial and occlusal surfaces of incisors and canines from hominins recovered from SH and compare them with those from the anterior teeth of Australian Aborigines, in order to further assess the possible extra-masticatory use of the anterior teeth from Sima de los Huesos.

\section{Materials}

The Sima de los Huesos (SH) site is a small cavity within the karstic system of Cueva Mayor-Cueva del Silo located at the southern slope of the Sierra de Atapuerca (Burgos, northern Spain). The first human remains were found in 1976 (Aguirre et al., 1976), and systematic excavations were started in 1984. The stratigraphy, sections of the SH site, and a map of the excavation grid have been published (Arsuaga et al., 1997a,b; Bischoff et al., 1997). All the human fossils were recovered from the same unit, which is formed by breccias of clay-supported bones, blocks, and clasts of variable thickness along the site profile (Bischoff et al., 1997). Apparently, all fossils came from the same sedimentation period (Bischoff et al., 1997). In this site, only human and carnivore remains (an import ant assemblage of Ursus deningeri fossils) have been found, while no herbivore remains have been discovered (Torres, 1978; García et al., 1997). Only a single lithic instrument (quartzite handaxe) has been recovered from this site (Carbonell et al., 2003).

Earlier radiometric and paleomagnetic analyses, as well as biochronological data, point to an age interval of 200-300 ka (OIS 7-9) or a minimum age of $350 \mathrm{ka}$ for the SH hominins (lischoff et al., 1997; Cuenca-Bescos et al., 1997; Pares et al., 2000; Bischoff et al., 2003). However, new high-precision dating on a recently discovered speleathem overlaying the human remains yielded new dates that cluster around $600 \mathrm{ka}$. The conservative conclusion of the authors takes the lower error limit ages as the minimum age of the spelothem, or $530 \mathrm{ka}$ (Bischoff et al., 2007).

The SH hominin sample comprises more than 5,500 fossil remains including all the skeletal elements, even the fragile ear bones (Martínez et al., 2008). We consider the SH hominin sample as representative of a biological population of Homo heidelbergensis (or European middle Pleistocene population). The minimum number of individuals (MNI) was assessed through the analysis of the maxilla, the mandibles (more than 50 remains), and teeth. The current sample includes a total of 479 teeth (109 in situ and 370 isolated teeth). Observations of all of these elements suggest that a minimum of 28 individuals are represented in the Sima de los Huesos hominin hypodigm (Bermúdez de Castro et al., 2004).

The dental fossil sample selected for this study comprises 163 teeth ( 110 incisors and 53 canines) that belong to 20 of the 28 individuals identified in SH. The eight remaining individuals do not have associated anterior teeth, and they have been excluded from this study. We also examined a sample of 49 third and fourth premolars from SH for one feature-vestibular stria-to test the hypothesis that this feature is found only in the anterior teeth, as should be the case if these features are related to paramasticatory activity. The other microwear features are examined only in the anterior dentition.

Sex and age-at-death of these individuals have been estimated by paleodemographic analysis (Rosas, 1997; Rosas et al., 2002; Bermúdez de Castro et al., 2004). Fight of these twenty individuals have been assigned as female, while seven are considered male. It has not been possible to identify the sex of the five remaining individuals. The ages-at-death of these twenty individuals range from 3-4 years for Individual IX (the only one with deciduous anterior teeth) to more than 35 years for individuals V and XXI. However, the great majority of individuals $(n=13)$ range from juveniles to young adult, between the ages of 9 and 19 years (Table 2).

We compared the SH sample to the teeth of Australian Aborigines, a population characterized by great dental wear and ethnographic evidence of the use of their anterior teeth as a third hand (Barrert, 1977; Brown and Molnar, 1990). These cranial remains are housed in the Duckworth Laboratory of the Leverhulme Centre for Human Evolutionary Studies at the Universily of Cambridge. The Australian sample is comprised of 185 teeth (112 incisors and 73 canines) from 31 individuals of different ages ranging from juveniles to adults, and of unidentified sex (Table 3). These individuals were from different regions of the Australian continent (Northwestern, Western, North Queensland, Queensland, Newcastle, and South Australia) and they lived between the end of the nineteenth century and the start of the twentieth century. Although Australian Aborigines have been reported to practice paramasticalory arivities with their teeth, it is not known whether these particular individuals did.

\section{Definitions of wear features scored}

Studies of microwear have generally indicated that the main microfeatures present on dental surfaces are scratches and pits (Ryan, 1979a,b; Teaford and Walker, 1984; Gordon, 1988; Ungar and Grine, 1991). Both types of features provide information about the diet of a certain species or human group. However, in the anterior teeth, other microfeatures related to ext ra-mastiratory uses of teeth are also present (1.alueza Fox, 1992; Lalueza Fox and Frayer, 1997; Bax and Ungar, 1999). Previous experimental work identified cutmarks of extra-masticalory origin on teeth (Lozano et al., 2004). We have identified and described the following wear features: clietary striations, vestibular striations, enamel flakes, vestibular-lingual striations, and polished enamel. We scored the occlusal attrition of each tooth following Skinner (1997: from Stage 0 for no attrition to Stage 8 for all crown worn away and root involvement). Then, the labial and occlusal surfaces of each tooth were examined microscopically for the marks defined below. Once recognized, these marks were then documented and measured as described below.

\section{Dietary striations}

Dietary striations are linear features with a rlearly perceptible angle of orientation (Gordon, 1988; Fig. 1a,b). The ratio between length and width can vary from 10:1 to $2: 1$, although some authors prefer to use the minimal proportion of $4: 1$. Dielary striations cover 


\begin{tabular}{|c|c|c|c|c|c|}
\hline \multirow[t]{2}{*}{ Individual } & \multirow[t]{2}{*}{ Age and sex } & \multirow[t]{2}{*}{ Inventory number and tooth } & \multicolumn{3}{|l|}{ Vestibular striations } \\
\hline & & & Length (sd) & Width (sd) & Orientation \\
\hline 1 & $16-17$ yrs Female & $\begin{array}{l}\text { AT-3193:RI } \\
\text { AT-3194: } \mathrm{LI}^{1} \\
\text { AT-283: } \mathrm{RI}^{2} \\
\text { AT-1754: } \mathrm{LI}^{2} \\
\text { AT-1460: } \mathrm{LI}_{1} \\
\text { AT-609: RI } \\
\text { AT-275: RI } \\
\text { AT-1464: } \mathrm{RI}_{2} \\
\text { AT-60: } \mathrm{R}_{\mathrm{C}} \\
\text { AT-276: } \mathrm{I}_{\mathrm{C}}\end{array}$ & $1306.8 \mu \mathrm{m}(513.5)$ & $41.3 \mu \mathrm{m}(18.8)$ & $\begin{array}{l}\mathrm{V}-13 \\
\mathrm{H}-16 \\
\mathrm{OD}-36 \\
\mathrm{OI}-7\end{array}$ \\
\hline II & $12.5-14.5$ yrs Indeterminate & $\begin{array}{l}\text { AT-42: } \mathrm{RI}^{1} \\
\text { AT-27: } \mathrm{LI}^{1} \\
\text { AT-2279: } \mathrm{LI}^{2} \\
\text { AT-162: RI } \\
\text { AT-55: RI } \\
\text { AT-597: } \mathrm{LI}_{2} \\
\text { AT-2: } \mathrm{R}_{\mathrm{C}} \\
\text { AT-578: } \mathrm{L}_{\mathrm{C}} \\
\text { AT-2027: } \mathrm{LPm}_{3} \\
\text { AT-603: } \mathrm{LPm}_{4}\end{array}$ & $1558.8 \mu \mathrm{m}(577.2)$ & $43.38 \mu \mathrm{m}(13.6)$ & $\begin{array}{l}\mathrm{V}-16 \\
\mathrm{H}-12 \\
\mathrm{OD}-52 \\
\mathrm{OI}-5\end{array}$ \\
\hline III & $15-17$ yrs Female & $\begin{array}{l}\text { AT-104: } \mathrm{LI}_{1} \\
\text { AT-1726: } \mathrm{RI}_{2} \\
\text { AT-103: } \mathrm{LI}_{2} \\
\text { AT-1952: } \mathrm{R}_{\mathrm{C}} \\
\text { AT-67: } \mathrm{I}_{\mathrm{C}} \\
\text { AT-149: } \mathrm{RPm}_{3} \\
\text { AT-47: } \mathrm{LPm}_{3} \\
\text { AT-28: } \mathrm{RPm}_{4}\end{array}$ & $1485.8 \mu \mathrm{m}(486.42)$ & $39.23 \mu \mathrm{m}(15.14)$ & $\begin{array}{l}\mathrm{V}-11 \\
\mathrm{H}-2 \\
\mathrm{OD}-23 \\
\mathrm{OI}-3\end{array}$ \\
\hline V & +35 yrs Indeterminate & $\begin{array}{l}\text { AT-2765: } \mathrm{LI}^{1} \\
\text { AT-3257: } \mathrm{LI}^{2} \\
\text { AT-2759: } \mathrm{R}^{\mathrm{C}} \\
\text { AT-2389: } \mathrm{RPm}^{3}\end{array}$ & $1476.32 \mu \mathrm{m}(549.1)$ & $41.5 \mu \mathrm{m}(14.3)$ & $\begin{array}{l}\mathrm{V}-1 \\
\mathrm{H}-0 \\
\mathrm{OD}-5 \\
\mathrm{OI}-2\end{array}$ \\
\hline VII & 24-30 yrs Male & $\begin{array}{l}\text { AT-553: RI } \\
\text { AT-554: }{ }^{1} \\
\text { AT-144: }{ }^{C} \\
\text { AT-163: } \mathrm{L}^{\mathrm{C}} \\
\text { AT-1469: RI } \\
\text { AT-555: } \mathrm{L}_{1} \\
\text { AT-5: RI } \\
\text { AT-195: } \mathrm{LI}_{2} \\
\text { AT-591: RC } \\
\text { AT-145: } \mathrm{L}_{\mathrm{C}} \\
\text { AT-24: RPm } \\
\text { AT-590: RPm } \\
\text { AT-64: } \mathrm{LPm}^{3}\end{array}$ & $1340.5 \mu \mathrm{m}(457.2)$ & $42.11 \mu \mathrm{m}(29.7)$ & $\begin{array}{l}\mathrm{V}-2 \\
\mathrm{H}-2 \\
\mathrm{OD}-12 \\
\mathrm{OI}-4\end{array}$ \\
\hline IX & $3-4$ yrs Indeterminate & AT-90: $L_{C}$ & $1613.6 \mu \mathrm{m}(546.54)$ & $33.3 \mu \mathrm{m}(23.2)$ & $\begin{array}{l}\mathrm{V}-\mathrm{O} \\
\mathrm{H}-0 \\
\mathrm{OD}-2 \\
\mathrm{OI}-0\end{array}$ \\
\hline $\mathrm{X}$ & $15-17$ yrs Female & AT-1951: $R_{C}$ & $1587.1 \mu \mathrm{m}(331.8)$ & - & $\begin{array}{l}\mathrm{V}-1 \\
\mathrm{H}-0 \\
\mathrm{OD}-1 \\
\mathrm{OI}-1\end{array}$ \\
\hline $\mathrm{XI}$ & 13-15 yrs Female & $\begin{array}{l}\text { AT-161: } \mathrm{RJ}_{2} \\
\text { AT-148: } \mathrm{RPm}_{3}\end{array}$ & $859.1 \mu \mathrm{m}(198.3)$ & $52.27 \mu \mathrm{m}(12.2)$ & $\begin{array}{l}\mathrm{V}-\mathrm{O} \\
\mathrm{H}-\mathrm{O} \\
\mathrm{OD}-3 \\
\mathrm{OI}-0\end{array}$ \\
\hline XII & $1-19$ yrs Male & $\begin{array}{l}\text { AT-300: } \mathrm{RJ}_{2} \\
\text { AT-300: } \mathrm{R}_{C} \\
\text { AT-300: } \mathrm{RPm}_{3}\end{array}$ & $1960.6 \mu \mathrm{m}(867.4)$ & -- & $\begin{array}{l}\mathrm{V}-2 \\
\mathrm{H}-0 \\
\mathrm{OD}-1 \\
\mathrm{OI}-1\end{array}$ \\
\hline$X V$ & $17-18$ yrs Female & $\begin{array}{l}\text { AT-1762: } \mathrm{LI}_{1} \\
\text { AT-1461: } \mathrm{I}_{2} \\
\text { AT-1753: } \mathrm{LI}_{2}\end{array}$ & $1312.1 \mu \mathrm{m}(332.7)$ & $21.1 \mu \mathrm{m}(10.8)$ & $\begin{array}{l}\mathrm{V}-4 \\
\mathrm{H}-0 \\
\mathrm{OD}-1\end{array}$ \\
\hline
\end{tabular}


Vestibular striations

Length (sd)

Width (sd)

Orientation

AT-2394: $\mathrm{R}_{C}$

AT-1755: $\mathrm{L}_{\mathrm{C}}$

XVI

12.5-14.5 yrs Indeterminate

XVIII

$X X$

XXI

XXII

XXIII

XXIV

12.5-14.5 yrs Indeterminate

XXV
9.5-11.5 yrs Male

$12.5-14.5$ yrs Male

+35 yrs Male

14-16 yrs Female

11-13 yrs Female
20-26 yrs Male
AT-2752: $\mathrm{LI}^{1}$ AT-2769: $\mathrm{RI}^{2}$ AT-2772: $\mathrm{LI}^{2}$ AT-2392: $\mathrm{L}^{\mathrm{C}}$

AT-3252: $\mathrm{LI}_{1}$

AT-3256: $\mathrm{RI}_{2}$

AT-2784: $R_{C}$

AT-2778: LC

AT-2758: $\mathrm{RPm}^{3}$

AT-2764: LPm $^{3}$

AT-2761: $\mathrm{LPm}_{3}$

AT-2395: RI ${ }^{1}$

AT-1143: $\mathrm{LI}^{1}$

AT-2280: $\mathrm{RJ}^{2}$

AT-1124: $\mathrm{RI}^{2}$

AT-2207: $R^{C}$

AT-2151: $\mathrm{L}^{\mathrm{C}}$

AT-2195: $\mathrm{RI}_{1}$

AT-2390: $\mathrm{LI}_{1}$

AT-957: $\mathrm{RI}_{2}$

AT-2066: $\mathrm{LI}_{2}$

AT-2165: $R_{C}$

AT-410: LC

AT-2399: $\mathrm{RPm}^{3}$

AT-2036: $\mathrm{LPm}^{3}$

AT-2343: $\mathrm{RPm}_{3}$

AT-2767: $\mathrm{LPm}_{3}$

AT-954: $\mathrm{RI}^{1}$

AT-953: $\mathrm{LI}^{1}$

AT-962: $\mathrm{RI}^{2}$

AT-820: $\mathrm{LI}^{2}$

AT-558: $R^{C}$

AT-955: $\mathrm{L}^{\mathrm{C}}$

AT-2730: $\mathrm{LI}_{1}$

AT-1123: $\mathrm{RI}_{2}$

AT-2783: $R_{C}$

AT-808: $\mathrm{L}_{\mathrm{C}}$

AT-589: $\mathrm{RPm}^{3}$

AT-809: $\mathrm{RPm}_{3}$

AT-3045: $\mathrm{LPm}_{3}$

AT-2773: $\mathrm{LI}^{1}$

AT-3192: $\mathrm{R}^{\mathrm{C}}$

AT-3258: $\mathrm{LI}_{1}$

AT-3251: $\mathrm{LI}_{2}$

AT-3891: $\mathrm{RPm}^{3}$

AT-3881: $\mathrm{LPm}^{3}$

AT-3195: $\mathrm{RI}^{2}$

AT-3191: $\mathrm{R}^{\mathrm{C}}$

AT-3250: $\mathrm{RI}_{1}$

AT-3199: $\mathrm{LI}_{1}$

AT-2753: $\mathrm{RI}_{2}$

AT-3198: $\mathrm{LI}_{2}$

AT-2766: $R_{C}$

AT-2768: $\mathrm{RPm}_{3}$

AT-3190: LPm $_{3}$

AT-595: $\mathrm{RI}_{1}$

AT-594: $\mathrm{RI}_{2}$

AT-607: $\mathrm{LI}_{2}$

AT-593: $R_{C}$

AT-607: LC

AT-607: $\mathrm{LPm}_{3}$

AT-607: LPm

AT-2388: $R^{C}$

AT-596: $\mathrm{RI}_{1}$

AT-281: $\mathrm{RI}_{2}$

AT-2391: $\mathrm{LI}_{2}$

AT-2438: $\mathrm{L}_{\mathrm{C}}$

AT-807: LPm $_{3}$

AT-3883: $\mathrm{RI}_{1}$

AT-3882: $\mathrm{LI}_{1}$

AT-3884: $\mathrm{RI}_{2}$
OI -2

$1506.2 \mu \mathrm{m}(511.1)$

$41.3 \mu \mathrm{m}(13.3)$

$\mathrm{V}-12$

$\mathrm{H}-0$

OD -22

$\mathrm{OI}-0$

$1687.4 \mu \mathrm{m}(880.7)$

$40.3 \mu \mathrm{m}(16.7)$

$\mathrm{V}-8$

$\mathrm{H}-8$

OD -29

OI -2

$1886.9 \mu \mathrm{m}(915.25)$

$51.84 \mu \mathrm{m}(18.7)$

$\mathrm{V}-9$

$\mathrm{H}-1$

OD -30

$\mathrm{OI}-0$

$1091.8 \mu \mathrm{m}(258.2)$

$1271.9 \mu \mathrm{m}(395.8)$

$42.7 \mu \mathrm{m}(13.3)$

$v-6$

$\mathrm{H}-\mathrm{O}$

$\mathrm{OD}-13$

$\mathrm{OI}-2$

$1213.6 \mu \mathrm{m}(376.5)$

$62.6 \mu \mathrm{m}(16.8)$

V -14

$\mathrm{H}-1$

OD -0

$\mathrm{OI}-3$

$1404.4 \mu \mathrm{m}(431.1)$

$41.3 \mu \mathrm{m}(17.1)$

$\mathrm{V}-5$

$\mathrm{H}-2$

OD -7

$\mathrm{OI}-0$

$1325.2 \mu \mathrm{m}(435.9)$
$\mathrm{V}-8$

$\mathrm{H}-1$

OD -9 
$\overline{\text { Vestibular striations }}$

Length (sd)

XXVII

20-26 yrs Male

XXXI

24-30 yrs Female
AT-3938: $L_{C}$

AT-3941: RPm3

AT-3940: $\mathrm{LPm}_{3}$

AT-3255: $\mathrm{R}^{\mathrm{C}}$

AT-3075: $\mathrm{L}^{\mathrm{C}}$

AT-2776: $\mathrm{LI}_{2}$

AT-1944: LPm $^{3}$

AT-814: $\mathrm{RI}^{1}$

AT-165: $\mathrm{LI}^{1}$

AT-3196: $\mathrm{LI}^{2}$

AT-219: $\mathrm{R}^{\mathrm{C}}$

AT-818: $L^{C}$

AT-3253: $\mathrm{RI}_{1}$

AT-2775: $\mathrm{LI}_{1}$

AT-2762: $\mathrm{L}_{C}$

Not assigned
AT-199: $\mathrm{RI}^{1}$

AT-54: $\mathrm{RI}^{1}$

AT-560: $\mathrm{LI}^{1}$

AT-1958: $\mathrm{LI}^{1}$

AT-280: $\mathrm{LI}^{1}$

AT-1943: $\mathrm{LI}^{1}$

AT-198: $\mathrm{LI}^{1}$

AT-3885: $\mathrm{LI}^{1}$

AT-8: $\mathrm{LI}^{1}$

AT-29: $\mathrm{LI}^{2}$

AT-2274: $\mathrm{RI}^{2}$

AT-1844: $\mathrm{RI}^{2}$

AT-1444: $\mathrm{RI}^{2}$

AT-1962: RI ${ }^{2}$

AT-1953: $\mathrm{LI}^{2}$

AT-7: $\mathrm{LI}^{2}$

AT-53: $\mathrm{LI}^{2}$

AT-961: $\mathrm{LI}^{2}$

AT-44: $R^{C}$

AT-1475: $R^{C}$

AT-1758: $R^{C}$

AT-825: $\mathrm{L}^{\mathrm{C}}$

AT-958: $\mathrm{L}^{\mathrm{C}}$

AT-1757: $\mathrm{L}^{\mathrm{C}}$

AT-6: $\mathrm{L}^{\mathrm{C}}$

AT-1492: $\mathrm{L}^{\mathrm{C}}$

AT-2397: $\mathrm{RI}_{1}$

AT-956: $\mathrm{RI}_{1}$

AT-166: RI

AT-4: $\mathrm{RI}_{1}$

AT-2384: $\mathrm{RI}_{1}$

AT-3241: $\mathrm{LI}_{1}$

AT-1474: $\mathrm{LI}_{1}$

AT-3242: $\mathrm{LI}_{1}$

AT-723: RI

AT-592: $\mathrm{RI}_{2}$

AT-282: $\mathrm{RI}_{2}$

AT-608: $\mathrm{LI}_{2}$

AT-2278: $\mathrm{LI}_{2}$

AT-167: $\mathrm{LI}_{2}$

AT-1960: $R_{C}$

AT-1144: $\mathrm{R}_{\mathrm{C}}$

AT-567: $L_{C}$

AT-164: $L_{C}$

AT-3186: $\mathrm{RPm}^{3}$

AT-2782: $\mathrm{LPm}^{3}$

AT-41: $\mathrm{LPm}^{3}$

AT-813: $\mathrm{LPm}^{3}$

AT-1466: RPm

AT-3185: $\mathrm{LPm}_{3}$

AT-563: $\mathrm{LPm}_{3}$

AT-3242: LPm

AT-1993: $\mathrm{LPm}_{3}$

AT-68: $\mathrm{RPm}^{4}$

AT-3189: LPm $^{4}$
$1599.6 \mu \mathrm{m}(657.2)$

$1590.7 \mu \mathrm{m}(509.05)$

$1566.2 \mu \mathrm{m}(451.1)$

(50.7 $\mu \mathrm{m}(50.05)$

$\begin{aligned} 60.8 \mu \mathrm{m}(19.1) & \mathrm{V}-2 \\ & \mathrm{H}-0 \\ & \mathrm{OD}-3 \\ & \mathrm{OI}-2 \\ & \mathrm{~V}-6 \\ & \mathrm{H}-0 \\ & \mathrm{OD}-15 \\ & \mathrm{OI}-2\end{aligned}$

$40.1 \mu \mathrm{m}(14.6)$

$\mathrm{V}-17$

$\mathrm{H}-\mathrm{g}$

OD -73

OI -19

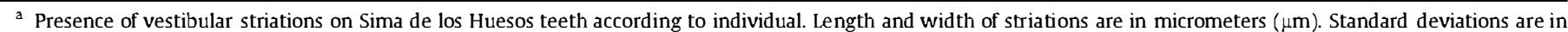
parentheses. Total number of vestibular striations according to orientation by individual. 
Table 3

The Australian Aborigine dental sample analyzed in this study

\begin{tabular}{|c|c|c|c|c|c|}
\hline \multirow[t]{2}{*}{ Individual } & \multirow[t]{2}{*}{ Origin } & \multirow[t]{2}{*}{ Age } & \multirow[t]{2}{*}{ Teeth } & \multicolumn{2}{|l|}{ Vestibular striations } \\
\hline & & & & length (sd) & Width (sd) \\
\hline Sth. Australia 2102 & River Murray, South Australia & Adult & $\mathrm{LI}^{2}, \mathrm{RI}^{2}, \mathrm{~L}-\mathrm{R}^{\mathrm{C}}, \mathrm{LI}_{1}, \mathrm{LI}_{2}, \mathrm{~L}_{\mathcal{C}}$, and $\mathrm{RI}_{2}$ & & \\
\hline Australia 2105 & .. & Adult & I. R R & & \\
\hline Sth. Australia 2122 & South Australia & Adult & $\mathrm{LI}^{2}-\mathrm{C}$ & & \\
\hline Sth. Australia 2130 & South Australia & Child & $\mathrm{RI}^{1}, \mathrm{Ld}^{\mathrm{C}}$ & & \\
\hline Sth. Australia 2131 & South Australia & Young adult & $\mathrm{L}-\mathrm{R} \mathrm{LI}_{1}-\mathrm{I}_{2}, \mathrm{I}_{c}$ & & \\
\hline Sth.W.Australian 2133 & South Australia & Adult & All front teeth & & \\
\hline Australia 2134 & - & Juvenile & $\mathrm{RI}^{1}$ and $\mathrm{R}^{\mathrm{C}}, \mathrm{LI}^{2}{ }^{\mathrm{C}}, \mathrm{L}-\mathrm{R} \mathrm{LI}_{1}, \mathrm{I}_{2}, \mathrm{C}$ & & \\
\hline Australia 2135 & Newcastle, New South Wales & Young adult & $\mathrm{L}-\mathrm{RI}^{2}-\mathrm{C}_{1} \mathrm{LI}_{2}$ & & \\
\hline Australia 2137 & - & Young adult & All front teeth & $482.7 \mu \mathrm{m}(304.5)$ & $25.3 \mu \mathrm{m}$ \\
\hline Australia 2142 & North Queensland & Adult & $\mathrm{L}^{\mathrm{C}}$ & $509 \mu \mathrm{mn}$ & $21.1 \mu \mathrm{m}$ \\
\hline Australia 2143 & - & Adult & $\mathrm{L}^{\mathrm{C}}, \mathrm{L}_{\mathrm{c}}$ & - & $35.3 \mu \mathrm{m}(5.5)$ \\
\hline Australia 2154 & - & Adult & $\mathrm{L}-\mathrm{R}^{\mathrm{C}}, \mathrm{R}_{\mathrm{C}}$ & & \\
\hline Australia 2158 & - & Adult & $\mathrm{L}-\mathrm{RI}^{2}{ }^{\mathrm{C}}, \mathrm{L}-\mathrm{RI}_{1}-\mathrm{I}_{2}, \mathrm{R}_{\mathrm{C}}$ & - & $61.45 \mu \mathrm{m}(11.7)$ \\
\hline Australia 2159 & & Young adult & $\mathrm{LI}^{1}, \mathrm{I}^{2}, \mathrm{C}_{;} ; \mathrm{RI}^{2},{ }^{\mathrm{C}} ; \mathrm{RI}_{2, \mathrm{c}} ; \mathrm{LI}_{1}, \mathrm{I}_{2}, \mathrm{c}$ & & $38.9 \mu \mathrm{m}(20.8)$ \\
\hline Australia 2160 & & Adult & $\mathrm{L}-\mathrm{RI}^{2}{ }^{2}{ }^{\mathrm{C}} ; \mathrm{RI}_{1} \mathrm{I}_{2, c} ; \mathrm{LI}_{2}, \mathrm{C}$ & & \\
\hline Australia 2161 & - & Young adult & $\mathrm{L}-\mathrm{RI}^{1} \mathrm{I}^{2} \mathrm{C}$ & & \\
\hline Australia 4509 & - & Adult & $\mathrm{L}-\mathrm{RI}^{2}$ & & \\
\hline Australia 6081 & River Murray, South Australia & Adult & $\mathrm{L}-\mathrm{R}^{\mathrm{C}}$ & - & $37 \mu \mathrm{m}$ \\
\hline Australian Aboriginal n5 & - & Adult & $\mathrm{LI}^{1}, \mathrm{I}^{2}, \mathrm{C}^{\prime} \mathrm{R}^{\mathrm{C}} ; \mathrm{L}-\mathrm{RI}_{1}, \mathrm{I}_{2}, \mathrm{C}$ & $711.4 \mu \mathrm{m}(466.1)$ & $37.2 \mu \mathrm{m}(6.9)$ \\
\hline Australia NW01 & Northwest Australia & Adult & $\mathrm{Ll}_{1}, \mathrm{I}_{2}$ & & \\
\hline Australian Aboriginal $n 3$ & - & Adult & $\mathrm{LI}^{1}, \mathrm{I}^{2}, \mathrm{C} ; \mathrm{R}^{\mathrm{C}}$ & - & $26.2 \mu \mathrm{m}$ \\
\hline Australia n05 & - & Adult & All front teeth & $742.5 \mu \mathrm{rn}(443.4)$ & $54.1 \mu \mathrm{m}(41.3)$ \\
\hline Australian Aboriginal n 6 & - & Juvenile & $\mathrm{RI}^{1}, \mathrm{I}^{2}, \mathrm{Cl}^{2},{ }^{\mathrm{C}} ; \mathrm{L}-\mathrm{RI}_{1,} \mathrm{I}_{2 \cdot \mathrm{C}}$ & $613.5 \mu \mathrm{rn}(201.5)$ & $56.9 \mu \mathrm{m}(29.2)$ \\
\hline Western Australia n7 & Baiong Tribe, Western Australia & Juvenile & $\mathrm{L}-\mathrm{R}^{2}{ }^{2} \mathrm{C}: \mathrm{RI}_{1}, \mathrm{I}_{2} ; \mathrm{L}_{\mathrm{C}}$ & $446.5 \mu \mathrm{m}(58.7)$ & $56.7 \mu \mathrm{rn}$ \\
\hline Australia NW7 & Northwest Australia & Adult & $\mathrm{RI}^{2}, \mathrm{~L}^{\mathrm{C}}: \mathrm{L}_{\mathrm{C}}$ & - & $69.4 \mu \mathrm{m}$ \\
\hline NW Australia NW2 & Northwest & Adult & $\mathrm{RI}^{2},-\mathrm{LI}^{2} ; \mathrm{RI}_{1}, \mathrm{LI}_{2}, \mathrm{~L}_{\mathcal{C}} ; \mathrm{LI}_{1}, \mathrm{LI}_{2}$ & & \\
\hline Northwest Australia 9 & Northwest Australia & Adult & I. $\mathbf{k I}^{\prime} ; \mathbf{k}^{\mathrm{r}} ; \mathrm{RI}_{1}, \mathrm{I}_{2,}, \mathrm{~L} ; \mathrm{LI}_{1}, \mathrm{I}_{2}$ & $1201 \mu \mathrm{mn}(281.4)$ & $58.3 \mu \mathrm{m}$ \\
\hline Northwest Australia n10 & Northwest Australia & Adult & $\mathbf{R}^{2} ; 1.1_{2 \mathbf{n}^{-}}$ & & \\
\hline Australia Oc 1.0.1 & Western Australia & Adult & $\mathbf{R I} \mathbf{I}^{2+} ; \mathbf{L}^{2}$ & & \\
\hline Australia Oc 0.0.1 & & Juvenile & $\mathbf{R I}^{\prime} ; \mathrm{LI}^{\prime} ; \mathbf{R}_{2}$ & & \\
\hline Australia Oc 3.0.1 & Queensland & Adult & 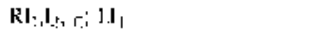 & $818 \mu \mathrm{rn}$ & $32.6 \mu \mathrm{m}(4.8)$ \\
\hline
\end{tabular}

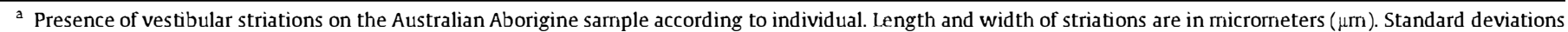
are in parentheses.

a range between 50 to $200 \mu \mathrm{m}$ in length (Lalueza Fox, 1996; PérezPérez et al., 1999), and width does not exceed $5 \mu \mathrm{m}$ (Peters, 1982; Ungar and Grine, 1991).

\section{Vestibular striations}

A simple ocular inspection of the crowns of incisors and canines of the SH sample identifies a set of striations that are arranged, more or Iess oblic|uely, on the labial surface (Fig. 2a,b) with a morphology that clearly differentiates them from dietary striations. This type of striation has also been identified on the front teeth of the Krapina Neandertals (Lalueza Fox and Frayer, 1997). The edges of these vestibular striations are linear, well-defined, and paralled to each other along most of their length. The bottoms of the striations ustually display a "V"-shaped transverse section and are ploughed by several parallel microscratches. Microscratches run longitudinally throughout the length of the groove of the striations. Small triangular liftings, or fractures in the borders of the striations called Hertzian cones, have sometimes been documented (Bromage and Boyde, 1984). These cones are the result of the interaction between the pressure exerted by the action of cutting and the resistance offered by the surface to be cut.

The morphological traits of vestibular striations are exactly the same as those displayed by cutmarks on bone (Shipman and Rose, 1984; Lozano et al., 2004), that is linear and parallel borders, the presence of Hertzian cones, grooves with a "V"-shaped section, and microscratches on the bottom of the striation (Fig. 3). The orientation of striations is an imporiant diagnostir characteristic because
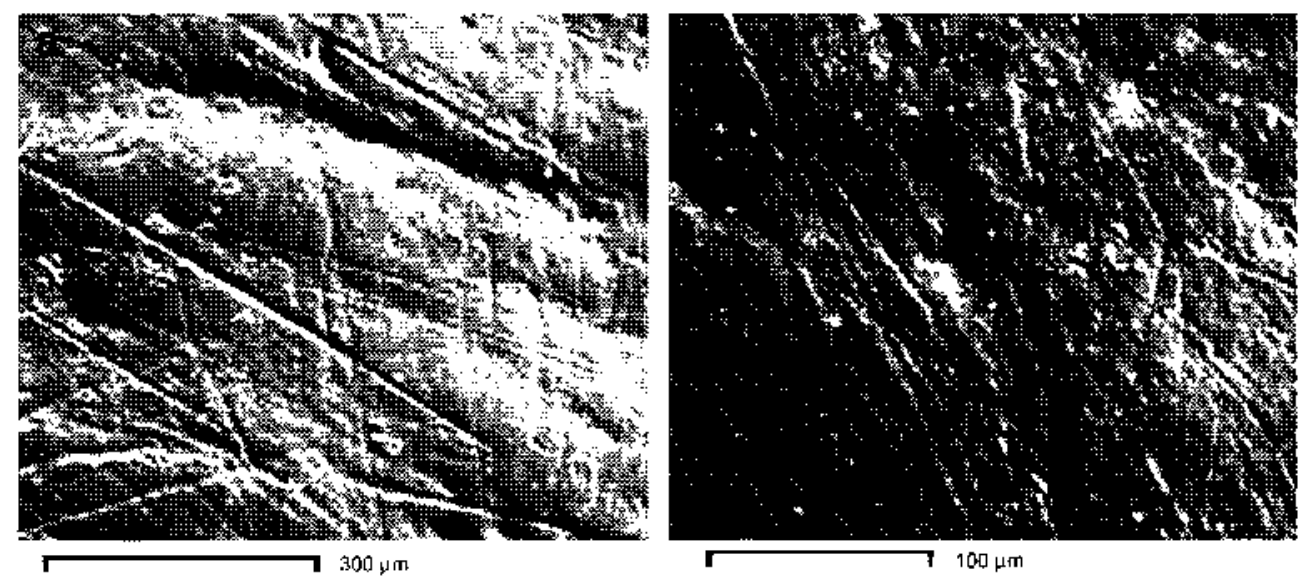

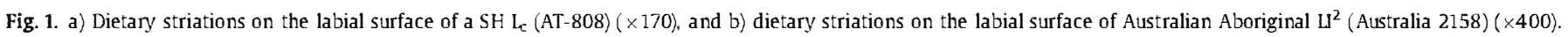



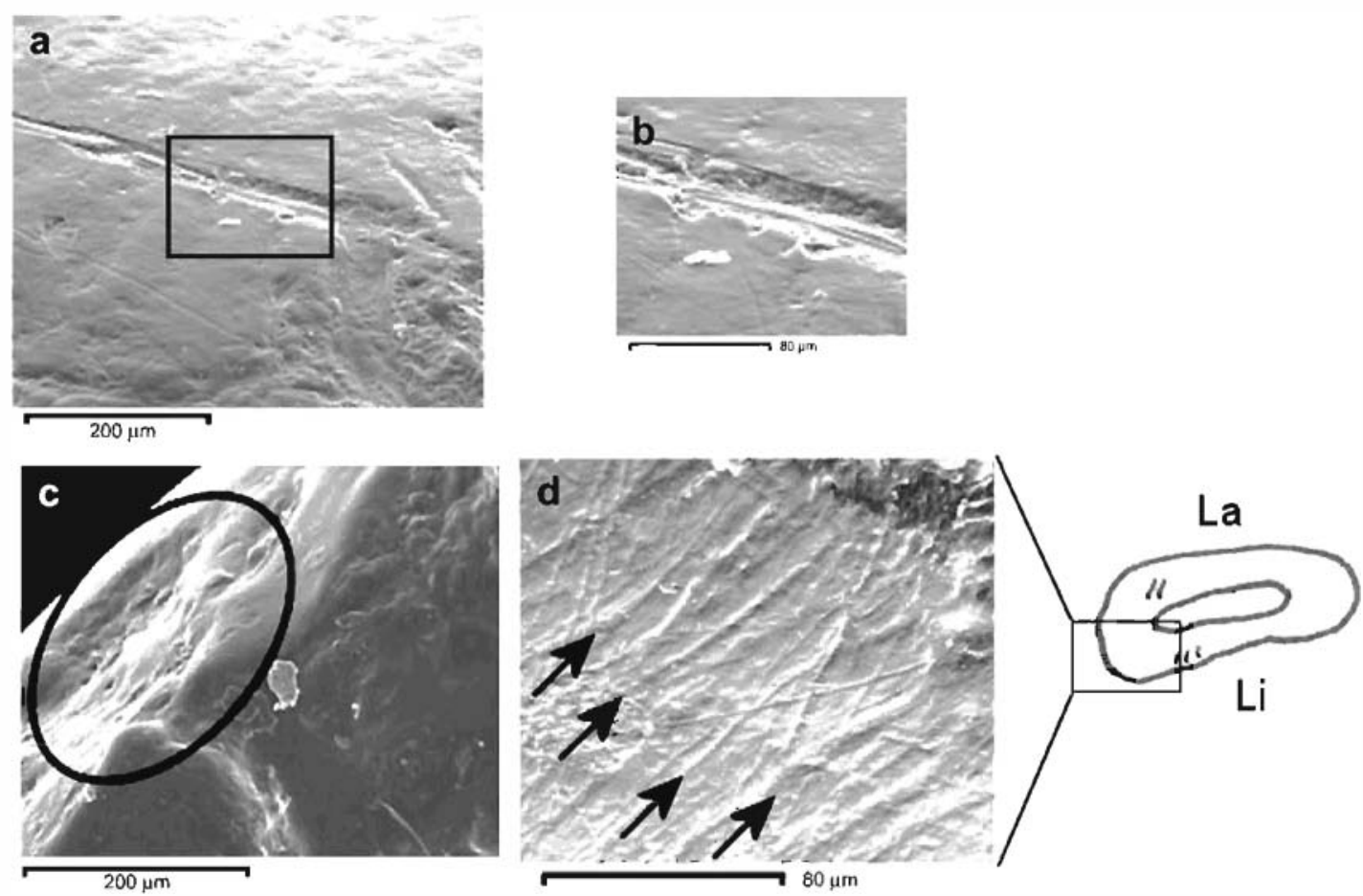

Fig. 2. Wear features of the SH sample: a) Vestibular striation with morphological traits similar to those displayed by cutmarks on bone. Labial surface of RI (AT-166) ( $\times 220$ ), b) detail of vestibular striation on labial surface of AT- $166(\times 700)$, c) enamel flake on the incisal border of $\mathrm{RI}_{1}(\mathrm{AT}-2397)(\times 270)$, and d) vestibular-lingual striations on enamel rim of incisal surface of $\mathrm{RI}^{2}$ (AT-1444) $(\times 700)$. The drawing shows the specific dentalarea in the occlusal surface with vestibular-lingual striations. La $=$ labial surface, Li=lingual surface.
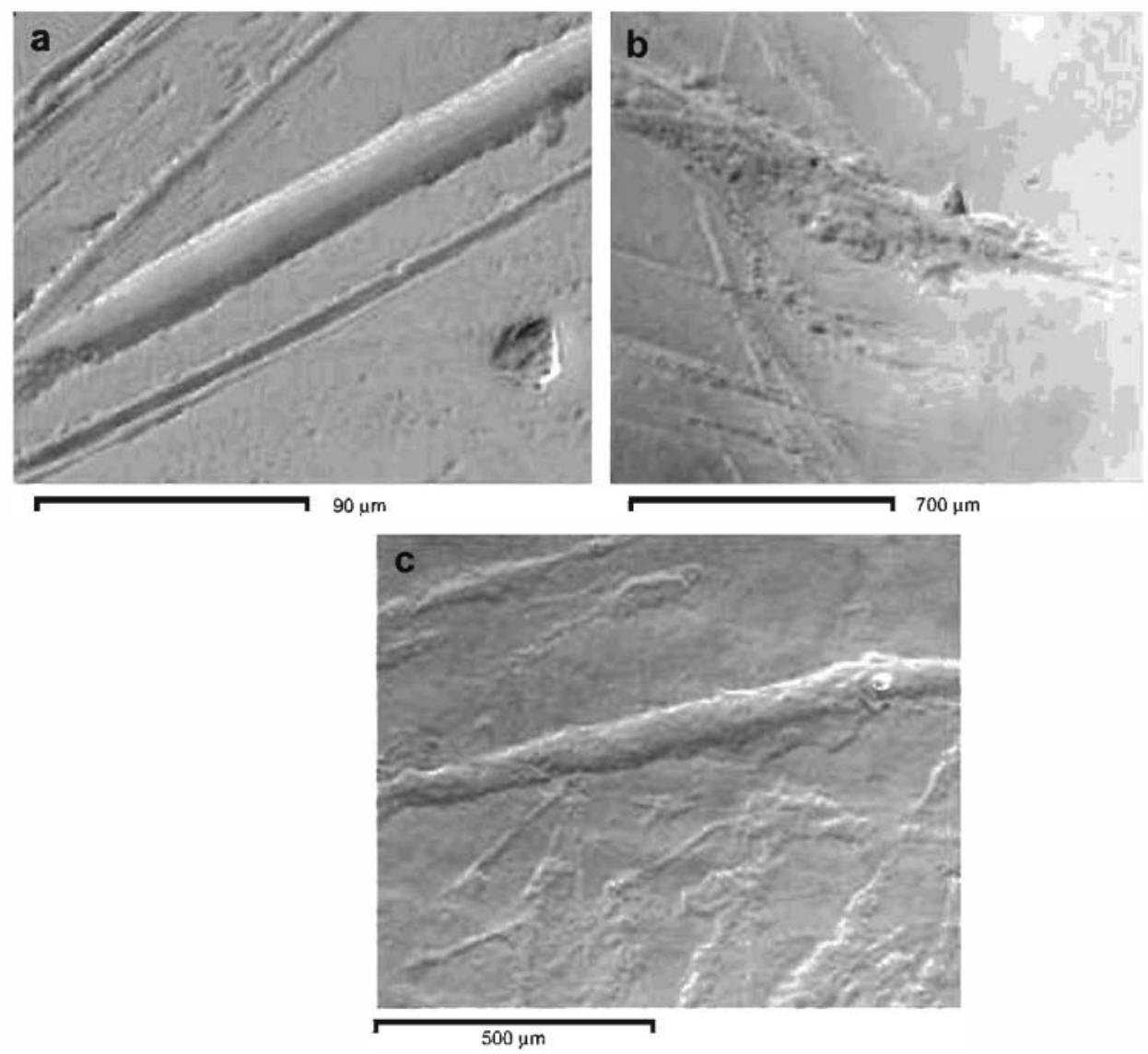

Fig. 3. a) Experimental cutmark made with a sandstone tool using the right hand $(x 600)$, b) experimental cutmark made with a flint tool using the left hand ( $x 75)$, and $c)$ vestibular striation on labial surface of $\mathrm{SH} \mathrm{RI}^{1}(\mathrm{AT}-42)(\times 400)$. Note the similarities in morphology and orientation between striations observed in $3 \mathrm{a}$ and $3 c$. 
right oblique $(\mathrm{RO})$ and vertical $(\mathrm{V})$ orientations are the most common (Fig. 4).

\section{Enamel flakes}

Enamel flakes are small pieces of enamel that have been removed by a blow or by pressure on the dental crown. The enamel that comes off the crown has the shape of a splinter or a flake. On the dental crown we can identify the negative impression that was left after the break. This impression is the record of the enamel flake.

Blows that produce flakes can have an ante- or postmortem origin. Flakes whose appearance is less well-defined are considered to have happened during the individuals' life (Turner and Cadien, 1971). In such cases, the outline of the break and the entire exposed surface is rounded, polished, and worn. Depending on the depth of the break, it is difficult to differentiate between the enamel and the underlying dentine. All these indicate an antemortem formation. The saliva, tongue action, and functional use of teeth have smoothed the contour of the break. This type of flake is often located on the incisal part of the labial surface in the contact zone between the labial and the occlusal surfaces, or on the occlusal surface, along the enamel rim that surrounds the exposed dentine at the border zones with other dental surfaces (Figs. $2 c$ and $5 b$ ). This type of wear has been previously identified in Eskimos and in Australian Aborigines by different researchers (Leigh, 1925; Merbs, 1968, 1983; Molnar, 1972).

\section{Vestibular-lingual striations}

These striations are only identified on the occlusal surface enamel and on the expnsed dentine. They are wear features of linear morphology that run along the occlusal surface in the vestibular-lingual direction. These striations suggest movement towards the front (vestibular) and back (lingual) of the mouth. Striations are generally perpendicular to the longiludinal axis of this surface. The striation borders, which run parallel to each other, have a rounded and polished appearance. These types of scratches have an internal well-defined groove with a rounded section, whose bottom does not present the microscratches indicated for vestibular striations. Hertzian cones on the borders are rare. Striations can be isolated on the occlusal surface, but the striations usually appear in parallel groups (Figs. $2 \mathrm{~d}$ and $5 c$ ). When vestibularlingual striations appear in a worn tooth with an enamel rim and a central area of exposed dentine, the striations can run on both types of dental tissues. They can cross the entire occlusal surface from the contact zone with the labial surface to the contact zone with the lingual surface. However, the striations on the exposed dentine seem to wear down and disappear more easily. Because of the softer nature of dentine, such striations may be maintained only on both sides of the enamel border. For this reason, most of the striations' groups have been documented on enamel. Many prehistoric groups display these types of striations including prehistoric Canary Islanders (Delgado Darias et al., 2001) and a Neolithic individual from Libya (Minozzi et al., 2003).

\section{Polished enamel}

Polished enamel can be defined as enamel areas that present a softened and smoothed appearance. These areas are devoid of other types of wear features such as striations, flakes, or pils. Polished enamel is generally fairly localized, thus other areas of the tooth may display other microfeatures (Puech, 1982).

\section{Microscopic methods}

In order to examine the dental sample by Scanning Electron Microscope (SEM), we obtained high resolution replicas of the original specimens. The dental sample of SH is in excellent condition for the replication of their surfaces. Dental surfaces are not covered with plaque and are not affected by dental cleray. Enamel is not eroded post-mortem. SH and Australian Aborigine teeth were cleaned with a soft brush soaked with acetone, and then soaked with distilled water in order to remove acetone residues. The replicas were made following a two-step process similar to that established by Rose (1983) and Pérez-Pérez et al. (1999). First, a mould of silicone-based dental impression material was made (Coltène President Regular Body). Then a polyurethane resin was

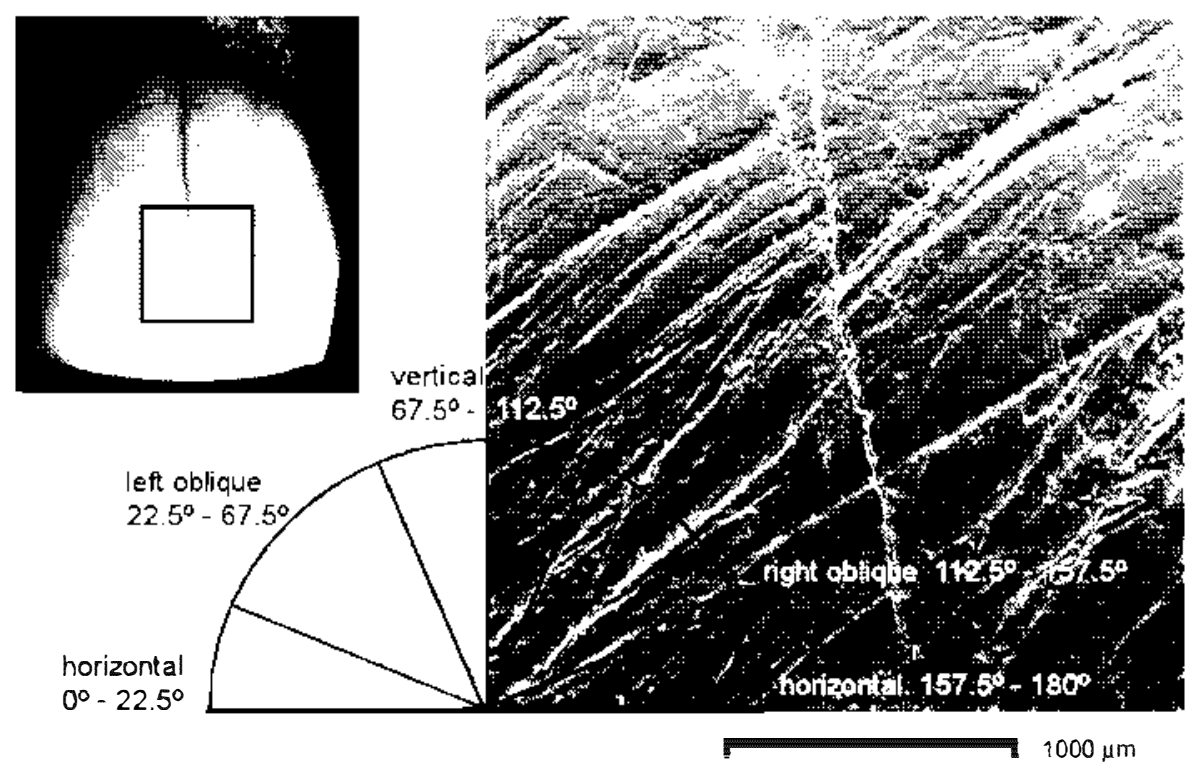

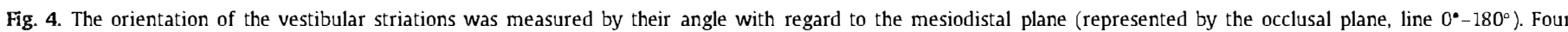

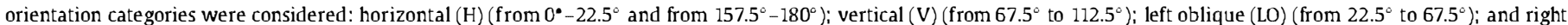

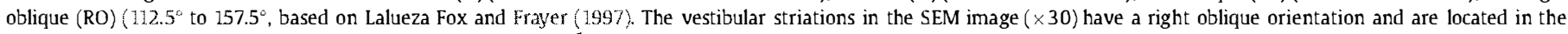
central part of the labial surface of the complete tooth AT-42 (RI) from Individual II of SH. 

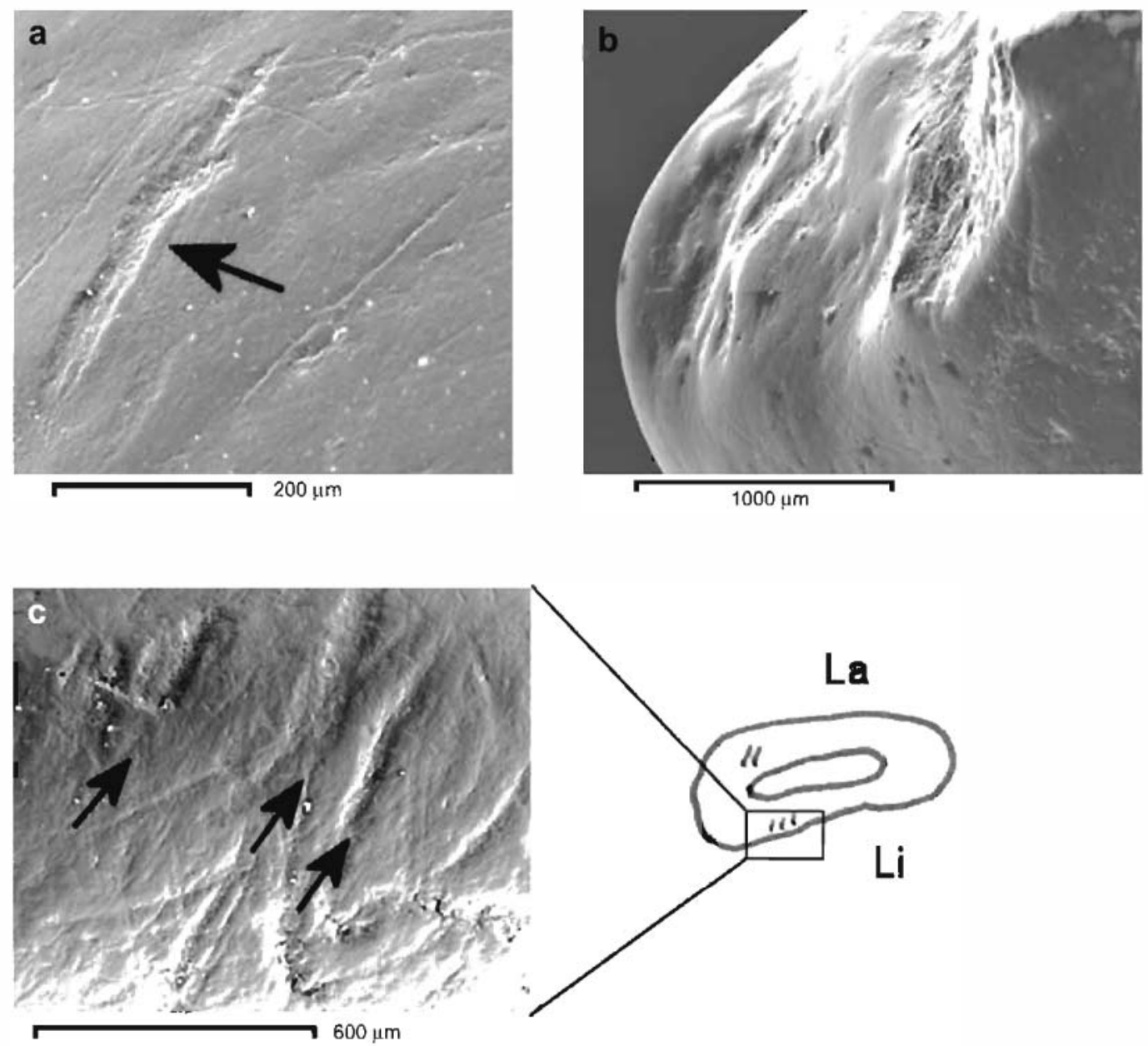

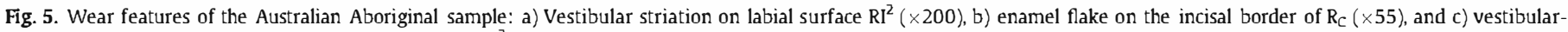

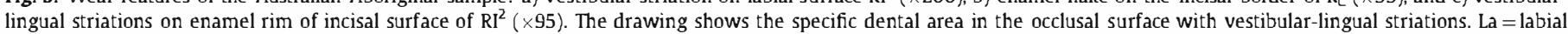
surface, $\mathrm{Li}=$ lingual surface.

introduced and left to harden for 10 minutes. This type of resin does not require centrifuging.

A detailed analysis of the labial and occlusal surfaces was performed with a SEM Jeol JSM 6400. Replicas are mounted on an aluminium stub and sputter coated in a High Vacuum Sputter Coater Unit (BAL-TEC Sputter Coated SCD 004) with a $25 \mathrm{~nm}$ gold layer. The area of contact between the specimen and the stub is painted with conductive graphite to ensure sample conductivity.

Replicas were examined by SEM in secondary electron emission mode with an accelerating voltage of $15 \mathrm{kv}$. Microwear dietary features have been studied on the basis of a protocol previously established. The analysis of the occlusal surface has been established to $500 \times$, and usually only the protoconid is analyzed (Teaford, 1991; Romero and de Juan, 2005; Mahoney, 2006). However, the analysis of buccal surfaces has generally been performed at 100× (Fine and Craig, 1981; Lalueza Fox, 1996; PérezPérez et al., 2003). This protocol cannot be applied to the nondietary microwear features because their morphology, disposition, and size require examination of a wider field of view. For this reason, replicas were first examined at a magnification of $43 \times$ and $100 \times$ to identify and locate the features of wear on each of the dental surfaces. The level of magnification was then increased gradually (up to $800 x$ ) to obtain a more detailed view of every type of feature. SEM digitized images were later obtained at different levels of magnification from chosen surfaces. All images were taken with tooth wear surfaces at a tilt angle of $0^{\circ}$ so as not to distort the size or shape of the wear features (Gordon, 1988).

The width and length of some features were measured directly in the digitized images (between $100 \times$ to $600 \times$ ) on the SEM screen using semiautomatic software for image-analysis (Microware 4.0) designed by Ungar (1995). However, the angles and lengths of vestibular striations were measured from digitized photographs obtained from an Olympus SZ11 stereomicroscope using different image-analysis software (MicroImage 3.0) because vestibular striations are several millimeters long and it is impossible to acquire images of the complete feature during SEM observation. Photographs were obtained with a JVC TK-C1381 camera connected to the binocular lens and to a computer. The photographs of labial surfaces with vestibular striations were taken at a magnification of $20 \times$. The orientation of the striations was measured by their angle with regard to the mesiodistal plane (represented by the occlusal plane, line $\left.0^{\circ}-180^{\circ}\right)$. Four orientation categories were considered: horizontal $(\mathrm{H})\left(\right.$ from $0^{\circ}-22.5^{\circ}$ and from $\left.157.5^{\circ}-180^{\circ}\right)$; vertical $(\mathrm{V})$ (from $67.5^{\circ}$ to $112.5^{\circ}$ ); left oblique (LO) (from $22.5^{\circ}$ to $67.5^{\circ}$ ); and right oblique (RO) $\left(112.5^{\circ}\right.$ to $157.5^{\circ}$, based on Lalueza Fox and Frayer, 1997; Fig. 4).

Statistical analyses focused on identifying significant microwear differences between the two samples. All variables (length, width, and orientation) of vestibular striations and vestibular-lingual striations show normal distributions based on the KolmogorovSmirnov test. Student's t-tests were conducted to evaluate if the 
group means were significatively different and took into account the small sample size. The means of all variables were determined by adding all the values together and dividing by number of affected individuals. Enamel flakes, vestibular-lingual striations, and polished enamel were compared using Chi- square tests in order to compare frequency groups. Chi-square is the best way to obtain qualitative data that have been classified in two mutually exclusive categories (presence or absence of a determined attribute). We have chosen the situation of more simple comparison, since the two groups ( $\mathrm{SH}$ and Australian Aborigines) have been compared regarding the qualitative variables with only one answer, that is, dichotomous variables.

Statistical significance was set at the $\mathrm{p} \leq 0.01$ level to minimize the probability of Type I error (Chandler, 1995).

\section{Results}

\section{Labial surface}

Dietary striations: In the two examined samples we have found striations whose etiology was diet-related (Fig. 1). In the SH sample there are 112 labial surfaces (68.7\% of the total sample; with this type of striation. All SH individuals showed this wear on the labial surface. These striations may be placed anywhere on the labial surface and they have different orientations within the same tooth. The average width of SH clietary striations is $1.93 \mu \mathrm{m}$ and the average length is $110.4 \mu \mathrm{m}$.

In the Australian Aborigine sample, 137 labial surfaces $75.7 \%$ of the total sample) show dietary striations. These striations are found anywhere on the labial surface and they have different orientations within the same tooth. The average dietary striation size is somewhat longer (233.4 micrometers) and wider (4.7 micrometers) in the Australians than in SH.

Vestibular scriacions: The percentage of anterior teeth with vestibular striations is $94.5 \%$ in the SH sample (i.e., 154 of the 163 incisors and canines have this type of striation). In contrast, only $6 \%$ of premolars ( 3 of 49 ) have vestibular striations at the occlusal third of the buccal surface. These results support the hypothesis that this feature is limited to the anterior teeth and related to paramasticatory aclivity. All $20 \mathrm{SH}$ individuals examined show this type of wear on all or on almost all anterior teeth.

In the Aboriginal sample we found 26 vestibular striations on 24 teeth (i.e., 13.3\% of the total sample). Striations were identified on the teeth of 15 of 31 individuals (i.e., $43.4 \%$ of the sample). The individuals affected belong to all age ranges except children. Fight of these fifteen individuals showed vestibular striations on only one tooth, while two or three teeth of the other seven were affected. Striations usually appeared on the incisal and central parts of the labial surface. The number of striations per tooth was also low: 22 out of 24 teeth had only one striation per tooth. Two individuals had two striations on one of their teeth.

Although in the SH sample there is certain variability in the number of striations found on each tooth, we can establish a general pattern of localization that relates closely to the wear of the crowns and the class of tooth. We iclentify three location patterns for vestibular striations in the SH sample: one corresponding to the incisors, one to the canines, and one to the premolars. In contrast, in the Australian sample there was no location preference in terms of dental category.

In SH, most vestibular striations are observed on incisors, particularly on the central upper incisors. On the teeth of young people, the striations are placed on the incisal and central parts of the labial surface. The older the individual, the greater the number of superimposed vestibular striations and the further across the labial surface they extend. In time, the crowns of teeth wear down because of the functional stress (Bermúdez de Castro et al., 2003), and the lower height of the crown seems to influence the location of wear features. Microfeatures tend to be located on the unworn surface, which is, logically, the cervical part. On adult individuals (over 16 years old), we have identified striations progressively nearer to the cervico-enamel junction, (i.e., closer to the gum). The extreme situation is observed in Individual XXI, who was possibly male and whose age was estimated at over 35 years. Few striations were located on his dentition probably because it was very worn down and the crowns were reduced to the enamel-cementum junction. This pattern is common to the upper and lower incisors.

Starting from the central point represented by the upper central incisors, we observed that the total number of vestibular striations decreases toward the distal part of the anterior teeth, (i.e., towards the cheek teeth). Therefore, the teeth with the fewest striations are canines and premolars. In canines, the vestibular striations were on the mesial part of the labial surface. The vestibular striations found on premolars are clear and isolated on the dental crown. One or two striations on each one of three premolars are therefore located in the vestibular-mesial region, near the atjacent canine.

The vestibular striations of the SH sample have a worn and polished appearance. Because of this polishing, in many instances the "V"-shape of the transverse section of the striations is worn and flat. Nevertheless, the presence of the internal groove has been identified in all striations. The characteristic microstriation has been well-preserved in $56.7 \%$ of vestibular striations. In $41.4 \%$ of the cases Hertzian cones appear on the margins of the striations. In the Australian sample, the bottom with the "V"'-shaped section was observed in all striations, and microscratches in the bottom of the groove were preserved in $15.4 \%$ of the cases. The presence of Hertzian cones was documented in seven teeth.

Several quantitative variables, such as width, length, and angle of orientation were measured. For the SH sample, mean width was obtained from 390 striations from 128 teeth $(81.5 \%$ of the total sample with vestibular striations). Two measurements of striation width were taken: in the central point of the striation, and in one of the ends, which are usually narrower than the center. The absolute average of the width is $43.2 \mu \mathrm{m}$ (Table 4 ). Individuals with wider striations are XXIII $(62.6 \mu \mathrm{m})$ and XXVII $(60.8 \mu \mathrm{m})$. The narrowest striations are from individuals XV $(21.1 \mu \mathrm{m})$ and XXI $(29.6 \mu \mathrm{m})$ (Table 2). Australian striation widths are similar because the average of the width of vestibular striations was $44.4 \mu \mathrm{m}$.

Vestibular striations are visible to the naked eye and are longer and wider than other microfeatures, such as dietary striations. For example, in the SH sample, dietary striations had a length of between 50.7 and $145.4 \mu \mathrm{m}$ (l'êre\%-l'ére\% et al., 1999), and clietary striation widths are always $<5 \mu \mathrm{m}$ (Peters, 1982; Ungar and Grine, 1991). The lengths of 592 vestibular striations from 139 SH teeth ( $88.5 \%$ of total sample with striations) were obtained in the present study (Tables 2 and 4 ). The mean length for the SH sample is $1507.3 \mu \mathrm{m}$ (597.6 s.d.). The individual with the longest vestibular striations is Individual XII $(1960.6 \mu \mathrm{m})$ and the individual with the shortest striations is Individual XI ( $85.1 \mu \mathrm{m}$; Table 2). In the Australian sample, the average length was $681.93 \mu \mathrm{m}$ (Table 3). In general, the Australian sample length was similar for all the individuals (Table 3).

Table 4

Vestibular striation mean width and length by sample

\begin{tabular}{lll}
\hline & Width (sd) & Length (sd) \\
\hline sinlit the los Hi:escrs & $47.2(17.8)$ & $1507.3(5.97 .5)$ \\
Al:srialian Alorigine & $44.4(18.7)$ & $681.9(364.2)$ \\
Experimental- righthanded & $39.7(15.8)$ & - \\
Experimental- lefthanded & $41.1(20.9)$ & - \\
Krapina & $25.5-67.7^{j}$ & $+6 \mathrm{~mm}$ \\
\hline
\end{tabular}

${ }^{a}$ Measurements are in micrometers :..mi, except for Kirpmin, length's which is in mm Data from Lalueza Fox and Frayer ( 1997:. 
Finally, we calculated the angle of orientation from the incisal edge of the tooth (i.e., the line we can draw across the incisal edge of the mesial surface to the distal surface; Fig. 4). We have obtained the angle of orientation of 592 striations from all the individuals in the SH sample. The category with the most striations is right oblique (RO), followed by vertical (V). The least represented categories are left oblique (LO) and horizontal (H). Only six individuals have striations of each orientation. The category that is generally not present is horizontal $(\mathrm{H})$, which was only documented in $50 \%$ of individuals. $\mathrm{RO}$ is the most common orientation for 15 individuals (I, II, III, V, VII, IX, XI, XVI, XVIII, XX, XXII, XXIV, XXV, XXVII, and $X X X I$; Table 2). The next most displayed orientation is vertical for four individuals (XII, XV, XXI, and XXIII). Only Individual X does not have preferred orientation. By dental category, the most common orientation is also RO. The second most documented orientation is vertical $(\mathrm{V})$. The null hypothesis that there are no significant differences with regard to the presence of vertical striations according to dental category was proposed. Upper incisors display a total of 222 striations, 36 of which are vertical. Lower incisors show 161 striations, 81 of which are vertical. The results of Chi-square tests of upper and lower incisors were $X^{2}=26.5382 ; \mathrm{df}=1 ; \mathrm{p}=0.0$. In other words, a significant difference with regard to the location of vertical striations exists. This type of striation was mainly found on the lower incisors. For the Australian sample, the predominant orientation was vertical ( $\mathrm{n}=9$ individuals), followed by horizontal $(n=3)$, left oblique $(n=2)$, and righr oblique $(n=1)$.

At $\mathrm{SH}$ the length and angle of orientation of vestibular striations were also related. Striations in RO were the longest, with an average of $1534.46 \mu \mathrm{m}$; followed by vertical striations, with an average of $1527.81 \mu \mathrm{m}$. The shortest striations were the horizontal ones, with an average of $1340.2 \mu \mathrm{m}$.

Size and shape of vestibular striations: Metric and descriptive analyses confirm that vestibular st jiat ions are cutmarks made with a lithic tool (Lozano et al., 2004). The arrangement of vestibular striations on the labial surface is a constant in all individuals in both the Australian and SH samples. The central and incisal parts are the most frequently affected zones on the labial surface in both samples. However, the total number of striations per tooth and per individual in the fossil sample differs from the Australian sample. The SH sample had an average of 29.5 vestibular striations per individual, whereas the Australian samizle had 1.7. The density of the vestibular striations was much greater in the SH sample than in the Australian sample. Use of the front teeth as a tool by SH hominins thus appears much more intense than in the Australian sample. If we take into account the absolute number of striations, the maxillary central incisors of the SH sample had the most vestibular striations. The location of these teeth in the central position of the maxilla means that they are easily exposed to lithic tools. This would explain the larger number of vestibular striations documented in the upper central incisors. A Student's t-test was conducted to check the homogeneity of this variable (i.e., the null hypothesis that the groups do not differ). The average width of the experimental striations was statistically homogeneous with that of the studied populations, because no p-values below the 0.01 significance level were found (Table 5). Moreover, the average width of
SH vestibular striations is also within the range documented for the Krapina Neandertals (Table 4 ; We can deduce that variable width helps to confirm the origin of the vestibular striations (i.e., vestibular marks are the result of the interaction of a lithic tool with the dental enamel). Morphology and width are the most homogeneous characteristics in the studied populations and the main indicators of the origin of these striations.

Enamel flakes: In the SH sample, we infer that 20 flakes were related to antemortem processes based on the presence of polished, rounded edges, which indicated that the wear process started during the individuals' life. These flakes have been documented on 20 of 163 incisors and canines (12.3\% of the total sample). Eleven of the twenty SH individuals (5.5\%) showed this wear feature on the labial surface. These individuals belonged to all of the age groups except infants and to both sexes.

In the Australian sample, only nine enamel flakes of an antemortem etiology were found, ( $5 \%$ of the total sample), located on the incisal part of the labial surface and generally in the contact zone with the occlusal surface. Sometimes two or three small flakes were documented along the vestibule-incisal rim. Only 4 out of 31 (12.9\%) Australians showed this feature.

A Chi-square test established a greater incidence of flakes in the fossil sample. In total, 55\% of SH individuals $(n=11)$ had flakes, while only $12.9 \%$ of Australians did ( $n::: 4$ ). A Chi-square test $\left(X^{2}=10.3768 ; d . f=1 ; p=0.001\right)$ confirmed that the SH sample had more enamel flakes.

\section{Occlusal surface}

The occlusal surfaces of SH individuals had a high degree of wear. Of 163 analyzed surfaces, 142 (87.1\% of total) had exposed dentine. Following Skinner (1997), 18 SH individuals had dentine exposure in stages from 4 to 7 . This percentage indicates a high rate of attrition if we consider that 13 of 20 individuals were aged between 9 and 19 years of age. The teeth of the Australians also showed a significant amount of attrition, since $81.1 \%$ of them had exposed dentine. Of 31 Aborigines, 29 (93.5\%) had exposed dentine on some of their anterior teeth. Of these, 27 individuals had dentine exposure in stages 4 to 7 .

Vestibular-lingual striations: All individuals in the SH sample show this type of wear, and 128 (78.5\%) of the anterior teeth of 20 individuals were affected. Canines most frequently lacked this kind of wear, perhaps because the sample is dominated by young people and they would have just erupted their canines. Measurements of 49 vestibular-lingual striations present in 14 fossil teeth were taken. The best preserved vestibular-lingual striations have been chosen. The mean width of these striations was $6.6 \mu \mathrm{m}$ and the mean length was $186.9 \mu \mathrm{m}$ (Table 6).

Australian Aborigines also had this type of wear: 55 teeth (29.7\%) belonging to 25 individuals of all age groups, except infants, were identified with this type of striation. The incidence per individual is $80.6 \%$, since 25 of 31 had at least one tooth with vestibulo-lingual striations. Length and width of these features were both greater in Australians than in SH. The mean length was $307.3 \mu \mathrm{m}$ and the mean width was $15.8 \mu \mathrm{m}$ (Table 6 ).

Table 5

Results of Student's t-test to check the homogeneity of maximum width and length of vestibular striations ${ }^{\mathrm{a}}$

\begin{tabular}{|c|c|c|c|c|c|}
\hline & \multicolumn{3}{|c|}{ Vestibular striations- maximum width } & \multicolumn{2}{|l|}{ Vestibular striations- length } \\
\hline & SH & $A A$ & EXP & $\mathrm{SH}$ & $A A$ \\
\hline $\mathrm{SH}$ & - & $0.74(t=0.1353 ; \mathrm{df}=412)$ & $0.11(t=0.6196 ; \mathrm{df}=516)$ & - & $0.00(t=2.637 ; \mathrm{df}=458)$ \\
\hline$A A$ & $0.74(t=0.1353 ; d f=412)$ & - & $0.31(t=0.4248 ; d f=150)$ & $0.00(t=2.637 ; \mathrm{df}=458)$ & - \\
\hline EXP & $0.11(t=0.6196 ; d f=516)$ & $0.31(t=0.4248 ; \mathrm{df}=150)$ & - & - & - \\
\hline
\end{tabular}

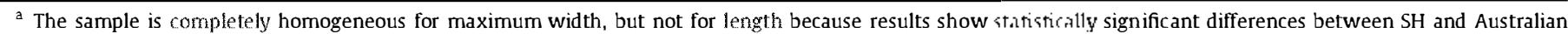
Aborigine samples. Numbers outside parentheses are the probability values. SH: Sima de los Huesos; AA: Australian Aboriginals; EXP: experimental. 


\begin{tabular}{lcc}
\hline & Width (sd) & Length (sd) \\
\hline SH & $6.6(3.9)$ & $186.9(119.1)$ \\
AA & $15.8(12.5)$ & $307.3(164.8)$ \\
\hline
\end{tabular}

Measurements are in micrometers $(\mu \mathrm{m})$.

Striations superimposed onto previous ones, indicating different formation times, were sometimes documented in both populations. A Chi-square test indicates that the two samples showed the same presence of this microfeature $\left(X^{2}=4,3870967 ; \mathrm{df}=1 ; \mathrm{p}=0.4\right)$. Twenty-five of thirty-one Australian Aborigines displayed vestibular-lingual striations, and all twenty SH individuals have these striations. The average striation length and width (Table 6) show that SH striations were narrower and shorter. Student's t-tests, however, showed that the width of these striations were not significantly different between samples (Table 7). Other Student's t-tests indicate that length does not differ significantly between the two samples (Table 7).

Enamel flakes: On the occlusal surface of the SH sample, 25 enamel flakes of antemortem etiology were documented $(15.3 \%$ of total teeth). The anterior teeth of 50\% of the individuals were affected $(n=10)$. Individuals with flakes cover a wide range of ages from 9.5-11.5 years (Individual XVIII) to over 35 years (Individual $\mathrm{V}$ ). The presence of flakes in $50 \%$ of the sample was not related to sex, age, or dental category.

In the Australian sample, $64.5 \%$ (20 out of 31 ) of individuals presented occlusal enamel flakes. Thirty-seven enamel flakes of antemortem etiology were documented. Most of these $(n=29)$ were found on the enamel rim of the incisors. The rest were documented on the canines. The presence of enamel flakes on Australian Aborigines $(\mathbf{n}=20)$ was not significantly different than that of individuals in the SH sample $(n=10),\left(X^{2}=1.0576 ; \mathrm{df}=1\right.$; $p=0.3$, i.e., both samples were equally affected by enamel flakes on occlusal surfaces).

Polished enamel: SH individuals had areas of polished enamel on 36 of the 163 examined surfaces, (22.1\% of the sample). No location preference could be established for this feature; it was documented in all dental categories. Of 20 individuals, 12 had areas of polished enamel. These belonged to both sexes and to different age groups, so we could not establish a location pattern for this feature based on sex or age. The main characteristic of this type of wear is the presence of zones of smooth, softened, and polished enamel on the occlusal surface.

Australians also showed polished enamel on 14 occlusal surfaces ( $7.6 \%$ of the total sample). The surfaces affected by polished enamel had different levels of wear, which, as in the fossil sample, were documented on surfaces without exposed dentine. In the Aboriginal sample, 9 out of 31 individuals (29\% of total sample) had polished enamel, often on more than one tooth. Statistically, SH individuals $(n=12)$ were more affected by polished enamel than were the Australians $(n=9)\left(X^{2}=11.3704 ; d f=1 ; p=0.00\right)$.

\section{Discussion}

Para- and non-masticatory activities imply that the anterior teeth were used as a tool for holding, pulling, or handling different materials. Holding materials such as meat, leather, or vegetable fibers between the front teeth and cutting them with a lithic tool in close proximity to the teeth can produce incisions on dental enamel. These cuts, called vestibular striations, have been documented on the teeth of all the individuals in the SH sample, regardless of sex or age. The Australian Aboriginal group also show vestibular striations, though to a lesser extent.

The other metric variables, on the other hand, provided very different results between the samples. The lengths of the vestibular striations in the SH sample were significantly different from those in the Australian sample (Table 5). In the SH sample, the average length was nearly twice as long as the average length in the Australian sample. Many of the vestibular striations of the $\mathrm{SH}$ sample were over $4 \mathrm{~mm}$ long, which is within the range documented for other individuals of the middle and Upper Pleistocene, such as Broken Hill, Tabun I, and La Quina 5 (Lalueza Fox and Frayer, 1997). The maximum length was found on vestibular striations of Krapina Neandertals because Lalueza Fox and Frayer (1997) measured vestibular striations over $6 \mathrm{~mm}$ (Table 4). The length of SH vestibular striations, longer than those of Australian striations, matched the range documented for other fossil hominins.

Metric analyses confirm that vestibular striations are a new microwear feature different than other diet-related features. However, to explain this point completely we should indicate that we have found striations whose etiology was diet-related in the two examined samples (Fig. 1). Measurements of these striations are very different than vestibular striations. This is a new argument in support of the different etiology of both features of microwear. The average width of SH dietary striations is $1.93 \mu \mathrm{m}$ and the average length is $110.39 \mu \mathrm{m}$. These measurements are clearly different from those belonging to the vestibular striations. Morphologically, both types of striations also differ (Fig. 1). For instance, the diet-related striations lack microscratches on the floor of their groove.

\section{Angle of orientation and laterality of vestibular striations}

We believe that the more frequent appearance of vertical striations on the lower incisors than in any other dental category is related to where the teeth are located relative to the material being held. When holding any material between the anterior teeth, the upper incisors are completely exposed to the exterior, whereas the lower ones are hidden by the material being held. When the lithic tool approaches the teeth to make the cut, the first to receive the impact are the upper incisors. Next, the material is cut and gives way, and the tool strikes against the lower incisors as it descends. Some ethnographic photographs show Eskimos cutting material with the knife held above the materials to cut (Faurie et al., 2005). This indicates that the direction of the cut is downwards, the logical way to avoid hurting ones' nose and face. The lower incisors have the most vertical vestibular striations because a vertical striation is

Table 7

Results of Student's t-test to check the homogeneity of measurements of vestibular-lingual striations ${ }^{\mathrm{a}}$

Vestibular-lingual striations

\begin{tabular}{|c|c|c|c|c|}
\hline & \multicolumn{2}{|l|}{ Width } & \multicolumn{2}{|l|}{ Length } \\
\hline & $\mathrm{SH}$ & $A A$ & $\mathrm{SH}$ & AA \\
\hline$\overline{\mathrm{SH}}$ & & $0.02(\mathrm{t}=2.6069 ; \mathrm{df}=58)$ & & $0.02(t=1.5382 ; \mathrm{df}=61)$ \\
\hline $\mathrm{AA}$ & $0.02(\mathrm{t}=2.6069 ; \mathrm{df}=58)$ & & $0.02(t=1.5382 ; \mathrm{df}=61)$ & \\
\hline
\end{tabular}

${ }^{a}$ Results present no statistically significant differences between SH and Australian Aborigine samples. Numbers outside of parentheses are the probability values. 
easily produced during the downward sliding movement of the hand.

Including the present study, the orientation of vestibular striations has been recorded in seven populations. Among these are five modern human samples: Aleutians (ALE), Arikara (ARI), Illinois Bluff (ILB), and Puye Indians (PU; Bax and Ungar, 1999), and two fossil samples: SH and Krapina (KRA; Lalueza Fox and Frayer, 1997; this study). Most individuals in the seven populations have a clear prevailing orientation of their vestibular striations (Fig. 6). The fossil samples ( $\mathrm{SH}$ and KRA) show a preference for the RO orientation. The modern samples, on the other hand, tend to show a vertical orientation. Thus, it is not feasible to infer manual laterality from the modern human samples, and Bax and Ungar (1999) infered that these striations do not provide information about laterality in fossil hominids. In previous work, however, Bermudez de Castro et al. (1988) and Lalueza Fox and Frayer (1997) have argued that the orientation of vestibular striations could provide information on laterality. Additionally, our experimental work (Lozano et al, 2004) suggests that $89.1 \%$ of vestibular striations made by right-handed individuals are $\mathrm{RO}$, and the remaining are vertical, while $78.4 \%$ of cutmarks made by left-handed individuals are LO, and the remainder are V. From these results and the distribution of orientations in the present study, we conclude that 15 $\mathrm{SH}$ individuals with a preferred orientation of $\mathrm{RO}$ were righthanded, or at least used their right hand to manipulate lithic tools. However, these experiments do not explain the manual laterality of the individuals with a preferred vertical orientation, since both left and right handed modern individuals made vertical striations. It remains to be determined why the prevailing orientation of modern groups is $\mathrm{V}$ and therefore not a valid indicator of laterality. This phenomenon may be related to the type of tool used, the way it is manipulated, and the type of activity performed.

\section{Other wear features}

The use of the dentition in para- and non-masticatory activities involves subjecting the anterior dental arcade, and especially the incisal border of the labial and occlusal surfaces, to great stress. Such stress can produce small fractures of the teeth. The existence of flakes on the incisal enamel of modern hunter-gatherers including Eskimos and Australian Aborigines has been documented (Leigh, 1925; Merbs, 1968, 1983; Turner and Cadien, 1971; Molnar, 1972). All these authors relate the presence of antemortem enamel

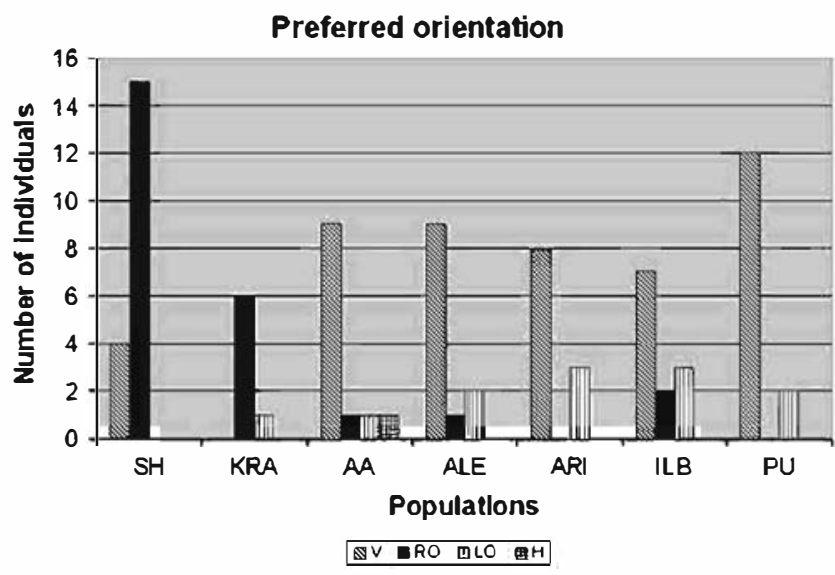

Fig. 6. Preferred orientation of vestibular striations of the SH sample, Krapina Neandertals (KRA), Australian Aboriginal (AA), Aleutian (ALE), Arikara (ARI), Illinois Bluff (ILB), and Puye Indians (PU). The fossil samples have a clear preference for right oblique (RO) orientation, and for the modern populations the preferred orientation is vertical (V). Data from Krapina are from Lalueza Fox and Frayer (1997) and data from ALE, ARI, ILB, and PU are from Bax and Ungar (1999). flakes to the use of the anterior dentition in activities that are unrelated to chewing. The presence of such flakes in SH individuals likely indicates that the anterior teeth were subjected to great stress, probably for holding and pulling various materials (e.g., skins, sinews, wood etc.). The greater presence of flakes in the SH sample may imply that these individuals carried out these activities more intensely than did individuals in our Australian sample. Flakes and breaks of the dental enamel also have been documented in other hominins, such as those from Tautavel (Puech, 1982). This is particularly interesting because the Tautavel hominins, with an age of 450,000 years BP, are from the same species as the SH hominins. Puech (1982) infers that the enamel flakes of the Tautavel hominins result from the action of repeated compressive forces that produce microfissures on the enamel, causing dental breakage as they enlarge. Puech (1982) also documented several zones of the occlusal enamel with a smooth, brilliant, and blunt appearance similar to the $12 \mathrm{SH}$ individuals who had polished enamel on some areas of their occlusal surfaces. The etiology suggested for the areas of polished enamel on the teeth of the Tautavel hominins is exposure to the repeated friction of their teeth against a pliable but resistant material, such as the cellulose and lignin of vegetables or the collagen of the animal tissues, when using their teeth as tools to grip these materials. We infer that this also explains the presence of the polished enamel of the SH sample.

The presence of vestibular-lingual striations, enamel flakes, and polished enamel on the occlusal surface of SH hominins support the hypotheses that the anterior teeth were used as a tool. We also found these wear features in Australian Aborigines, a population known ethnographically to use their anterior teeth as tools (Barrett, 1977; Collier, 1983; Brown and Molnar, 1990). Australian Aborigines use their anterior teeth for many activities such as holding, slicing, cutting, and pulling different kinds of materials, such as vegetable fibers, dry emu, and kangaroo sinews. One of the tasks frequently carried out is the removal of the bark from branches in order to manufacture digging sticks (Barrett, 1977). The bark is usually dry and this causes a great deal of abrasion on the occlusal and labial surfaces of the teeth. The formation of vestibular-lingual striations must mainly be related to the handling of flexible materials. Several Eskimo groups have been seen to perform certain activities with their anterior and/or posterior dentition. The most widely documented of these activities is the chewing and pulling of the dry skins of caribou and seal in order to soften them (Ryan and Johanson, 1989). Eskimos also prepare threads from the sinews of these animals. This procedure involves holding one end of the sinew with the anterior teeth and separating the various threads with the hands. The threads are used to sew furs, holding them between the anterior teeth and a hand, and sewing them with the other. The wear produced by these tasks is characterized by grooves on the occlusal surface. The vestibular-lingual striations may be related to this type of activity since the direction followed suggests a movement towards the front (vestibular) and back (lingual). All of the SH individuals had vestibular-lingual striations, which implies holding and stretching materials between the anterior teeth was a habit common to the entire group. The width and length of the vestibular-lingual striations are statistically homogeneous for the SH and Australian groups (Table 7). We can conclude that vestibular-lingual striations are produced by handling materials of similar thickness (i.e., sinews, skins, or vegetal fibers). SH hominins probably had access to these types of materials in a similar way as did Australian Aborigine groups (Barrett, 1977; Brown and Molnar, 1990).

The processed materials must have been sufficiently abrasive to wear down the dental enamel. Sinews, nerves, skins, and vegetable fiber strips such as barks and branches can cause this type of wear. SH hominins had access to the sinews, nerves, and skins of the animals they hunted and scavenged (Huguet, 1997; Rosell, 2001; 
Cáceres, 2002). Evidence of the processing of leather has been found in lithic tools on levels TD10-1a and TD10 of the Gran Dolina site (Sierra de Atapuerca, Spain; Márquez et al., 2001) with a chronology of $337 \pm 29 \mathrm{ka}$ and $377 \pm 29 \mathrm{ka}$ (Uranium series and ESR; Falguères et al., 1999).

Similarly, at Sierra de Atapuerca the hominins would have had access to herbaceous and arboreal plants for processing vegetable fibers. Pollen analyses have identified, in levels of similar chronology to SH, Pinus, Olea, and Quercus (Carcia Antón, 1998). The processing of vegetables for domestic use has also been determined by analysing the wear of lithic tools from Sierra de Atapuerca sites (Márquez et al., 2001).

In addition to the ethnographic parallels and inferences from evidence found at other sites of Sierra de Atapuerca, we can support the results of this investigation with archaeological parallels. Two individuals found at the Natufian necropolis of Mallaha (Israel) show a kind of dental wear that has been related to the use of anterior teeth for non-masticatory activities (Bocquentin et al., 2005). The occlusal surfaces of the incisors and canines are altered by some grooves that indicate the manipulation of vegetable fibers (e.g., stems, barks, and leaves). The authors of that study suggest that the microscratches inside the grooves were the result of a mechanical movement when plaiting fibers rlasped between teeth to make cordages. Similar wear has been documented on the teeth of prehistoric individuals in Gran Canaria (Spain; Delgado Darias et al., 2001). The striations of these individuals have a rectilinear development with a parallel disposition between them that sometimes form authentic groups. Other populations with documented grooves on the occlusal surfaces of anterior teeth are the Native Americans from the Great Plains, the north-western coast natives of California and Texas, and individuals from Greenland and Syria (Larsen et al., 1998). We have also found important similarities between the vestibular-lingual striations of SH hominins and striations on the teeth of a Libyan Neolithic population (Minozzi et al., 2003). At the Uan Muhuggiag site, the skeleton of an adult male exhibited several grooves on occlusal surfaces ranging from 1.6 to $3.2 \mathrm{~mm}$ in width. When these grooves were examined under SEM, a set of vestibular-lingual microscratches were discovered inside the furrow. The width of these microscratches is $8.5 \pm 0.3 \mu \mathrm{m}$. This size matches the average width of the vestihular-lingual striations of SH $(6.6 \pm 3.9 \mu \mathrm{m}$; Table 6). In all cases, the disposition and direction of the grooves indicates the processing of flexible materials between the teeth. Interpretations of the activities performed vary according to the human group. In the case of Native Americans, this dental wear is related to the processing of vegetable fibers. In the case of Nordic populations, such as Greenlanders and Eskimos, it is related to the processing of sinews and animal skins.

An etiology suggested by the above researchers is the processing of vegetable fibers. We cannot suggest that SH individuals perform such complex tasks as the manufacturing of nets or baskets, but we can suggest that they manipulated skins and sinews to make clothing or cordages. Vegetables have been processed to separate the bark from branches in order to manufacture digging sticks with which to obtain roots and tubers or to soften fibers for making cordages. This hypothesis is supported by lithic microwear studies that have determined the presence of lithic wood-working in Sierra de Atapuerca's sites of similar chronology to SH (Márquez et al., 2001; Vergès, 2003).

The vescibular-lingual striations of the occlusal surface are likely related to the vestibular striations of the labial surface. Holding materials between the teeth in order to cut them would produce both types of striations. Contact marks between the lithic tools and the dental enamel would be produced, and tightening materials in order to cut them would produce vestibular-lingual striations. The large number and overlap of some groups of striations on the SH individuals indicate that these activities were probably everyday activities carried out over a lifetime.

We can therefore state that the results obtained from the occlusal surface support the evidence previously presented for the labial surface. All the microfeatures we have documented imply that SH hominins used their anterior teeth as a tool. The stuff-andcut technique would lead to vestibular striations on the labial surface of the anterior teeth (Brace. 1967; Brace et al., 1987) of both studied populations.

Finally, it is interesting that extra-masticatory activities led not only to tooth damage but also to a high degree of occlusal wear and degenerative conditions. The high pressures and bite forces exercised caused damage to the temporomandibular joint. Some of the SH individuals (Skull 4, 5, and 6) are affected by temporomandibular arthropathy. The high frequency of this arthropathy, even in immature individuals -6 out of 8 individuals that preserve the articular region of the temporal bone are affected (Pérez and Martínez, 1995; Pérez and Gracia, 1998; may imply that there was an intense and continued extramastiratory use of the front part of the dental arcade.

Para- and non-masticatory tasks appear to have been performed by all the members of the group, regarclless of sex or age. This suggests that the SH hominins belonged to human groups with a social cohesion in which children learned these roles by observing and imitating adult behaviors and habits. This shows that these hominins of the middle Pleistocene attained a high degree of social complexity. Such a high degree of complexity is not restricted to SH hominins, however, since those from Tautavel and Mauer also showed microfeatures related to the use of the teeth as a third hand (Puech, 1982): This type of behavior would have been generated with Homo heidelbergensis and reached other species, such as the Neandertals. We do not have documented evidences of vestibular striations in earlier Homo species, such as Homo erectus.

Using the anterior teeth as a tool for holding and cutting material must be understood as a way that these hominins adapted one part of their bocly to compensate for a lack of certain tools. These hominins must therefore have attained a higher degree of behavioral complexity than earlier Homo species (i.e.., they must have developed the ability to exploit their environment beyond the basic objective of consuming food in order to survive?.

\section{Conclusions}

The high degree of dental wear documented on the anterior teeth of SH individuals is the result of a combination of the standard function of these teeth (the processing of foodstuffs prior to ingestion) and the performance of non-masticatory tasks. Certain dental wear features are consistent with the proressing of some of these resources for manufacture of clothing, cordages, and wooden implements. These wear features were also documented in the Australian Aborigine sample, a population with ethnographic evidence of the use of the teeth as a third hand.

Moreover, the orientation of vestibular striations shows that 15 out of $20 \mathrm{SH}$ individuals were right-handed. We therefore propose the existence of manual laterality in Homo heidtlbergensis at least 400,000 years ago.

\section{Acknowledgemients}

We are gratefiul to Xosé Pedro Rodríguez, and to all of the people who helped us in the experimental work for their helpful collaboration. We are also gr ateful to Marta M. Lahr and Maggie Bellatti of the Leverhulme Centre for Human livolutinnary Studies at the University of Cambridge because they allowed Marina Lozano to obtain replicas of the original Australian Aborigine sample. Mercé Moncusí and Mariana Stefanova helped us in the use of the SEM. 
The Dirección General de Investigación of the Spanish M.E.C., Project $\mathrm{N}^{\circ}$ CGL.2006-13532-C03, supported this research. Funding for the fieldwork came from the Consejería de Cultura y Turismo of the Junta de Castilla y León and the Fundación Atapuerca.

\section{References}

Aguirre, E., Basabe, J.M., Torres, T.J., 1976. Los fósiles humanos de Atapuerca (Burgos): nota preliminar. Zephyrus 26-27, 489-512.

Arsuaga, J.L, Martínez, I., Gracia, A., Lorenzo, C., 1997a. Sima de los Huesos (Sierra de Atapuerca, Spain): the site. J. Hum. Evol. 33, 109-127.

Arsuaga, J.L., Martínez, I., Gracia, A., Lorenzo, C., 1997b. The Sima de los Huesos crania (Sierra de Atapuerca, Spain): a comparative study. J. Hum. Evol. 33, 219-281.

Barrett, M.J., 1977. Masticatory and non-masticatory uses of teeth. In: Wright (Ed.), Stone Tools as Cultural Markers: Change Evolution and Complexity. Australian Institute of Aboriginal Studies, Canberra, pp. 18-23.

Bax, J., Ungar, P., 1999. Incisor labial surface wear striations in modern humans and their implications for handedness in Middle and Late Pleistocene Hominids. Int J. Osteoarchaeol. 9, 189-198.

Bermúdez de Castro, J.M., Bromage, T., Fernández-Jalvo, Y., 1988. Buccal striations on fossil human anterior teeth: evidence of handedness in the middle and early Upper Pleistocene. J. Hum. Evol. 17, 403-412.

Bermúdez de Castro, J.M., Martinón-Torres, M., Lozano, M., Sarmiento, S., Muela, A. 2004. Palaeodemography of the Atapuerca-SH hominin sample: a revision and new approaches to the palaeodemography of the European Middle Pleistocene population. J. Anthropol. Res. 60, 5-26.

Bermúdez de Castro, J.M., Martinón-Torres, M., Sarmiento, S., Lozano, M., Arsuaga, J. L. Carbonell, E., 2003. Rates of anterior teeth wear in Middle Pleistocene hominins from Sima de los Huesos (Sierra de Atapuerca, Spain). Proc. Natl. Acad. Sci. U. S. A. 100 (21), 11992-11996.

Bischoff, J.L, Fitzpatrick, J.A., León, L, Arsuaga, J.L, Falgueres, C, Bahain, J.J., Bullen, T. 1997. Geology and preliminary dating of the hominid-bearing sedimentary fill of the Sima de los Huesos Chamber, Cueva Mayor of the Sierra de Atapuerca, Burgos, Spain. J. Hum. Evol. 33, 129-154

Bischoff, J.L., Shamp, D.D., Aramburu, A., Arsuaga, J.L., Carbonell, E., Bermúdez de Castro, J.M., 2003. The Sima de los Huesos hominids date to beyond U/Th equilibrium (>350 Kyr) and perhaps to 400-500 Kyr: new radiometric dates. J. Archaeol. Sci. 30, 275-280.

Bischoff, J.L., Williams, R, Rosenbauer, R., Aramburu, A., Arsuaga, J.L, García, N., Cuenca-Bescós, G., 2007. High-resolution U-series dates from the Sima de los Huesos hominids yields $600+\infty$ kyrs: implications for the evolution of the early Neanderthal lineage. J. Archaeol. Sci. 34, 763-770.

Bocquentin, F., Sellier, P., Murail, P., 2005. Abrasion dentaire et travail spécialisé dans la population natoufienne de Mallaha (Israël). C.R Palevol. 4 (4), 351-357.

Brace, C.L. 1967. Environment, tooth form, and size in the Pleistocene. J. Dent. Res. $46,809-816$

Brace, C.L, Mahler, P.E, 1971. Post-Pleistocene changes in the human dentition. Am J. Phys. Anthropol. 34, 191-204.

Brace, C.L., Molnar, S., 1967. Experimental studies in human tooth wear: I. Am. J Phys. Anthropol. 27, 213-222.

Brace, C.L., Rosenberg, K.R., Hunt, K.D., 1987. Gradual change in human tooth size in the Late Pleistocene and post-Pleistocene. Evolution 41, 705-720.

Bromage, T.G. Boyde, A., 1984. Microscopic criteria for the determination of directionality cutmarks on bone. Am. J. Phys. Anthropol. 66, 359-366.

Brown, T., Molnar, S., 1990. Interproximal grooving and task activity in Australia. Am. J. Phys. Anthropol. 81, 545-553.

Cáceres, I., 2002. Tafonomía de los yacimientos antrópicos en karst Complejo galería (Sierra de Atapuerca, Burgos), Vanguard Cave (Gibraltar) y Abric Romaní (Capellades, Barcelona). Ph.D. Dissertation, Rovira i Virgili University.

Carbonell, E, Mosquera, M., Ollé, A., Rodriguez, X.P., Sala, R., Vergès, J.M., Arsuaga, J. L. Bermúdez de Castro, J.M., 2003. Les premiers comportements funeraires auraint-ils pris place à Atapuerca, il y a 350,000 ans? L'Anthropol. 107, 1-14

Chandler, C.R, 1995. Practical considerations in the use of simultaneous inference for multiple tests. Anim. Behav. 49, 524-527.

Collier, S., 1983. Australian aboriginal immature dentition. Available from: http:// www.sfu.ca/archaeology/dept/theses/masters/collier.htm.

Cuenca-Bescos, G., Conesa, C.L., Canudo, J.I., Arsuaga, J.L., 1997. Small mammals from Sima de los Huesos. J. Hum. Evol. 33, 175-190.

Delgado Darias, T., Velasco Vázquez, J., Arnay de la Rosa, M., González Reimers, E., 2001. Huellas de actividad en piezas dentarias de la población prehispánica de Gran Canaria: I. Congreso de Análisis Funcional de España y Portugal, Barcelona, pp. 22-28.

Falguères, C., Bahain, J.J., Yokoyama, Y., Arsuaga, J.L., Bermúdez de Castro, J.M. Carbonell, E., Bischoff, J.L., Dolo, J.M., 1999. Earliest humans in Europe: the age of TD6 Gran Dolina, Atapuerca, Spain. J. Hum. Evol. 37, 343-352.

Faurie, C., Schiefenhövel, W., Bomin, S., Billiard, S., Raymond, M., 2005. Variation in the frequency of left-handedness in traditional societies. Curr. Anthropol. 46, 142-147.

Fine, D., Craig, G.T., 1981. Buccal surface wear of human premolar and molar teeth: a potential indicator of dietary and social differentation. J. Hum. Evol. 10 335-344.

García Antón, M., 1998. Reconstrucciones de paleovegetación en Atapuerca según análisis polínico. In: Aguirre (Ed.), Atapuerca y la Evolución Humana. Fundación Ramón Areces, Madrid, pp. 61-71. Huesos Middle Pleistocene site (Sierra de Atapuerca, Spain). J. Hum. Evol. 33. $155-174$.

Gordon, K.D., 1988. A review of methodology and quantification in dental microwear analysis. Scan. Microsc. 2, 1139-1147.

Green, T.J., Cochran, B., Fenton, T., Woods, J.C., Titmus, G., Tieszen, L, Davis, M.A., Miller, S., 1998. The Buhl burial: a paleoindian woman from southern Idaho. Am Antiq. $63,437-456$

Huguet, R, 1997. Estudi zooarqueològic de la unitat GII del complex galería (Sierra de Atapuerca, Burgos). M.A. Thesis, Rovira i Virgili University.

Kaifu, Y., 2000. Tooth wear and compensatory modification of the anterior dentoalveolar complex in humans. Am. J. Phys. Anthropol. 111, 369-392.

Kaifu, Y., Kasai, K, Townsend, G., Richards, L.C., 2003. Tooth wear and the "design" of the human dentition: a perspective from evolutionary medicine. Am. J. Phys. Anthropol. 46, 47-61.

Lalueza Fox, C., 1992. Information obtained from the microscopic examination of cultural striations in human dentition. Int. J. Osteoarchaeol. 2, 155-169.

Lalueza Fox, C., 1996. Les restes humanes del jaciment epipaleolític de la Balma de Guilanyà (Navès, Solsonès). Pyrenae 27, 279-285.

Lalueza Fox, C. Frayer, D.W., 1997. Non-dietary marks in the anterior dentition of the Krapina Neanderthals. Int. J. Osteoarchaeol. 7, 133-149.

Lalueza Fox, C., Pérez- Pérez, A., 1994. Cutmarks and post-mortem striations in fossil human teeth. J. Hum. Evol. 9, 165-172.

Larsen, C.S., Teaford, M.F., Sandford, M.K., 1998. Teeth as tools at Tutu: extramasticatory behavior in prehistoric St Thomas, U.S. Virgin Islands. In: Lucaks (Ed.), Human Dental Development, Morphology and Pathology: A Tribute to Albert A. Dahlberg. University of Oregon, Eugene, pp. 402-420.

Leigh, RW., 1925. Dental pathology of the Eskimo. Dent. Cosmos 67, 884-898.

Lozano, M., 2005. Estudio del desgaste a nivel microscópico de los dientes anteriores de los homínidos del yacimiento pleistocénico de Sima de los Huesos (Sierra de Atapuerca, Burgos). Ph.D. Dissertation, Rovira i Virgili University.

Lozano, M., Bermúdez de Castro, J.M., Martinón-Torres, M., Sarmiento, S., 2004 Cutmarks on fossil human anterior teeth of the Sima de los Huesos site (Atapuerca, Spain). J. Archaeol. Sci. 31, 1127-1135.

Lukacs, J., Pastor, R., 1988. Activity-induced patterns of dental abrasion in prehistoric Pakistan: evidence from Mehgarh and Harappa. Am. J. Phys. Anthropol. 76, 377-398.

de Lumley, M.A., 1973. Anténéandertaliens et nándertaliens du bassin méditerranéen occidental européen. Laboratoire de Paleontologie Humaine et de Prehistoire, Marsella (Études Quaternaires. Géologie, Paléontologie, Préhistoire, Mémoire 2)

Mahoney, P., 2006. Microwear and morphology: functional relationships between human dental microwear and the mandible. J. Hum. Evol. 50, 452-459.

Márquez, B., Ollé, A., Sala, R, Vergés, J.M., 2001. Perspectives méthodologiques de l'analyse fonctionnelle des ensembles lithiques du Pléistocène inférieur et moyen d'Atapuerca (Burgos, Espagne). L'Anthropol. 105, 281-299.

Martinez, I., Arsuaga, J.L., Quam, R, Carretero, J.M., Gracia, A., Rodriguez, L, 2008. Human hyoid bones from the middle Pleistocene site of the Sima de los Huesos (Sierra de Atapuerca, Spain). J. Hum. Evol. 54, 118-124.

Merbs, C., 1968. Anterior tooth loss in Arctic populations. SW. J. Anthropol. 28 20-32.

Merbs, C., 1983. Patterns of Activity-induced Pathology in a Canadian Inuit Population. National Museums of Canada, Ottawa, paper 119.

Minozzi, S., Manzi, G., Ricci, F., Lernia, S.D., Borgognini-Tarli, S.M., 2003. Nonalimentary tooth use in prehistory: an example from Early Holocene in Central Sahara (Uan Muhuggiag, Tadrart Acacus, Libya). Am. J. Phys. Anthropol. $120,225-232$.

Molnar, S., 1971. Human tooth wear, tooth function and cultural variabilitiy. Am. J. Phys. Anthropol. 34, 175-190.

Molnar, S., 1972. Tooth wear and culture: a survey of tooth functions among some prehistoric populations. Curr. Anthropol. 13, 511-526.

Pares, J.M., Pérez-González, A., Weil, A.B., Arsuaga, J.L., 2000. On the age of the hominid fossils at the Sima de los Huesos, Sierra de Atapuerca, Spain: paleomagnetic evidence. Am. J. Phys. Anthropol. 111, 451-461.

Pérez-Pérez, A., Bermúdez de Castro, J.M., Arsuaga, J.L., 1999. Nonocclusal dental microwear analysis of 300,000 year-old Homo heidelbergensis teeth from Sima de los Huesos (Sierra de Atapuerca, Spain). Am. J. Phys. Anthropol. 108, 433-457.

Pérez-Pérez, A., Espurz, V., Bermúdez de Castro, J.M., de Lumley, M.A., Turbón, D., 2003. Non-occlusal dental microwear variability in a sample of Middle and Late Pleistocene human populations from Europe and the Near East. J. Hum. Evol. 44, 497-513.

Pérez, P.J., Gracia, A., 1998. Los homínidos de Atapuerca: información sobre modos de vida a partir de datos paleoepidemiológicos. In: Aguirre, E. (Ed.), Atapuerca y la Evolución Humana. Fundación Ramón Areces, Madrid, pp. 333-360.

Pérez, P.J., Martínez, I., 1995. New evidence of temporomandibular arthrosis in human fossils from the middle Pleistocene site of Atapuerca/Ibeas, Burgos, Spain. In: Batista, R, Campillo, D., Carreras, T. (Eds.), Proceedings of the IXth European Meeting of the Paleopathology Association. Barcelona, 1st-4th September, 1992. Museu d'Arqueologia de Catalunya, Barcelona, pp. 267-272.

Peters, C., 1982. Electron-optical microscopic study of incipient dental microdamage from experimental seed and bone crushing. Am. J. Phys. Anthropol. 57, 283-301.

Puech, P.F., 1979. The diet of early man: evidence from abrasion of teeth and tools. Curr. Anthropol. 20, 590-592.

Puech, P.F., 1982. L'usure dentaire de l'homme de Tautavel. L'Homo erectus et la place de l'homme de Tautavel parmi les hominidés fossiles. Colloque International du CNRS, Nice, pp. 249-274. 


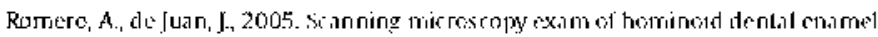
surface: explaring the effect af abrasives in the diet. In: Wendez-Vilas, A., Labajos-

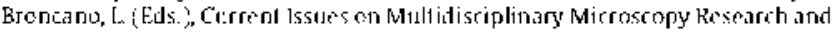

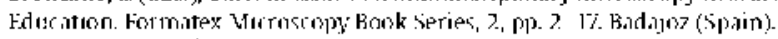

Rosas, A., 1997. A gradient af size and shape tor the Alapecerca sample and Middle Plesstocene hommet vartahily. J. Humi. Fvol. 33, 719731.

Rosas, A. Bastir. M., Marlínez-Maza. C.. Bermilidez de Castro. J.M., 2002. Sexual

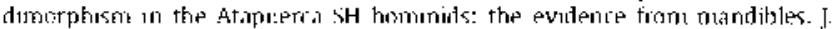
Findi. Evol. 42, 451-474.

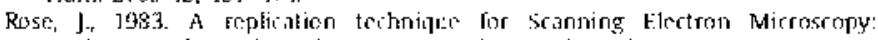
applications for anthropologists. Am. J. Phys. Anthropol, 62, 255-261.

Rosell, J., 2001. Patrons d'Aprobilament de les biomassus animals dutant el plestorè Infersor I Wig (Sierra de Atapuerca. Butgos) i Superior (Abric Romani, Barcelonaj. Jh.lo. Jisiertation, Rovira i Virgil1 ilnuversily.

Ryan, A.S., 1979a. W'ear striation drection on primate teeth: a scanning electron ricroscope examination. Am. J. Phys. Anthropol. 50. 155-168.

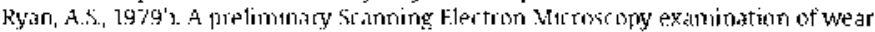
striation direction on primate teeth. J. DenL Res. 58, 525-530.

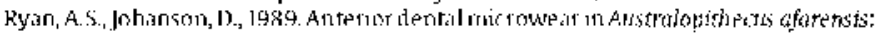
comparisons with human and nonhuman primates. J. Hum. Evol. 18, 235-268.

Shipman, P., Rose, J., 1984. Cutmark mimics on modern and fossil bones. Curr. Anttiropol. 2? I?, 116-117.

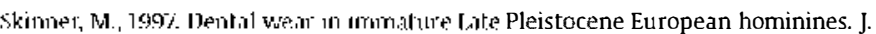
Archatol. Sci. 24, 677-700.

Teaford, M., 1991. Jental nicrowem: what con th tell us about diet and dental fitnction? In: Kelley, A., Larson, C.S. 'Eds.', Advances in Dental Anthropology. Wilcy-Liss, pp. 341-356.

Teatord, M., Walker, A., 1984. Quantitative differences in dental microwear jetween primate specics with diffesent diets and a comment on the prest:med diet of Sivapitheriss. Anu J. Phys Anthropol. 64, 191-200.

Torres, T., 1978. Ilistórica de la excavación de Atapuerca 1976. In: Bérmídez de Castro, l.m. (F.t.i, f.1 Hombre Fósil de Ibeas $y$ el Pleistoceno de la Sierta de Atapuerca. Junta de Castilla y León, Valladolid, pp. 37-38.

Timk.n1s, F., 1983. The Shanidar Neandertals. Acadenic Press, New York.

Turner, C., Cadien, 1.D., 1971. Dental chipping in Aleuts. Eskimos and Indians. Am. J Plhys. Anthropoll. $71,303.310$.

Ungar. P., 1995. A semiat:tomated jomate analissis procedure for the quantificalion of dental microwcar: It. Scanning 17,57-59.

Ungar, P.S., Grine, F.E., 1991. Incisor size and wear in Austrotopir hecus ajricunus and Paranthropus rob̀ustis. J. Hun. Evol. 20, 313-340

Vergès, J.M., 2003. Caracterització dels models d’instrumental lític del mode I a partir de les dades de l'anàlısi funcional dels conjunts lutotècnics t'Ain Hanech 1 el kherba Algextia, Monte Poggiolo I lserna la Puneta (Itàlas. Ph.D. Dissertation, Rovira i Virgili Jniversity. 